\title{
Why Parthood Might Be a Four-Place Relation, and How it Behaves If It Is ${ }^{1}$
}

\author{
Cody Gilmore
}

Version of 11 May 2009

Forthcoming in Ludger Honnefelder, Edmund Runggaldier, and Benedikt Schick, eds., Unity and Time in Metaphysics (Berlin: de Gruyter)

\section{Introduction}

Compositional monism is the view that there is exactly one fundamental parthood relation, i.e., exactly one parthood relation that does not have an analysis in terms of some more natural ${ }^{2}$ parthood relation. Compositional pluralism is the view that there are multiple such relations, perhaps associated with different ontological categories and possessing different, though overlapping, sets of formal properties. ${ }^{3}$ (These terms are from McDaniel (2004 and forthcoming).)

One assumption is widely shared by philosophers on both sides of this dispute - viz., that there is just one fundamental parthood relation that can hold between one material object and another. I will make this assumption too, and I will call the relation in question parthood $_{m}$.

One of the central questions about this relation is The Adicity Question: What is the adicity of parthood ${ }_{\mathrm{m}}$ ? The most widely accepted answer is that parthood $_{\mathrm{m}}$ is a two-place relation, with one slot for a part, another slot for a whole, and no further slots. Theodore Sider has defended this view and given it a name-

Absoluteness:

The main rival to Absoluteness is

Three-Place Parthood (3P):
Parthood [or at least parthood $\mathrm{d}_{\mathrm{m}}$ is a two-place relation; it does not hold relative to times, places, sortals, or anything else (2007: 70).

\author{
Three-Place Parthood $(3 \mathrm{P}):$
}

Parthood $_{m}$ is a three-place relation that can be expressed by the predicate ' $\mathrm{x}$ is a part $\mathrm{m}$ of $\mathrm{y}$ at z'.

3P is popular with those who hold that at least some material objects are multi-located in spacetime, exactly occupying ${ }^{4}$ (or being 'wholly present at') each of two or more spacetime

\footnotetext{
${ }^{1}$ I am grateful to Yuri Balashov, Ben Caplan, Greg Damico, Scott Dixon, Maureen Donnelly, Hud Hudson, Kris McDaniel, and Adam Sennet for very helpful comments.

${ }^{2}$ The notion of relative naturalness is from Lewis (1986a: 59-69): the more natural properties and relations are the ones that do a better job of 'carving nature at its joints' than the less natural ones; sharing them does more to make for genuine resemblance than the sharing of less natural properties and relations.

${ }^{3}$ E.g., there may be one fundamental parthood relation that holds between states of affairs and their constituents, another that holds between complex universals and their constituents, another that holds between events and their constituents, etc. McDaniel (2004) defends compositional pluralism. Sider (2007) defends compositional monism.

4 'Exactly occupies' is usually left undefined. Informally, though, the idea is supposed to be that an object $\mathrm{O}$ exactly occupies a spacetime region $\mathrm{R}$ just in case $\mathrm{O}$ has (or has-at- $\mathrm{R}$ ) precisely the same shape, size, and position as R. Thus big spheres exactly occupy only big spherical regions, etc. Moreover, there should be nothing obviously impossible about the claim that a thing exactly occupies each of two or more non-pointsized regions but not their sum or any of their proper subregions. It is worth noting that while this
} 
regions. ${ }^{5}$ These philosophers typically want to allow that a material object can have different parts $_{\mathrm{m}}$ at different regions. (Or at different times, but since the philosophers in question think of times merely as spacetime regions of a special sort, this hedge isn't really needed.) Accordingly, friends of $3 \mathrm{P}$ often say that the third slot in $\operatorname{parthood}_{\mathrm{m}}$ can be filled by a spacetime region. This would make room for the possibility of an object that is a part $\mathrm{m}_{\mathrm{m}}$ of a second object at one region but not at another.

In this paper I consider an alternative to Absoluteness and 3P, namely

Four-Place Parthood (4P): $\quad$ Parthood $_{m}$ is a four-place relation that can be expressed by the predicate ' $\mathrm{x}$ at $\mathrm{w}$ is a part $\mathrm{m}$ of $\mathrm{y}$ at $z^{\prime}$.

It will be natural, though not officially required, for friends of $4 \mathrm{P}$ to say that parthood $\mathrm{m}_{\mathrm{m}}$ has one slot for a part, a second slot for a location of that part (e.g., a spacetime region), a third slot for a whole, and a fourth slot for a location of that whole (e.g., a spacetime region). I will argue that much of the support for 3P is misplaced and should be redirected toward 4P. Specifically, my main conclusion will be that anyone who accepts the thesis of multi-location mentioned above should prefer $4 \mathrm{P}$ to $3 \mathrm{P}^{6}$

This is a diverse group. It includes endurantists ${ }^{7}$ who say that a material object exactly occupies each in a series of temporally unextended 'slices' of its spacetime path (Mellor 1980, van Inwagen 1990, Rea 1998, Sattig 2006). But it also includes Hud Hudson (2001), who accepts a form of perdurantism ${ }^{8}$ according to which ordinary material objects are multi-located 'spacetime worms' that exactly occupy many, mostly overlapping, four-dimensional spacetime regions. Finally, it includes the proponents of a certain position in the metaphysics of modality namely, the Modal Realism with Overlap (MRO) set out by Kris McDaniel (2004). On this view, at least some material objects are 'wholly present' in many different concrete possible worlds; any such object would exactly occupy at least one different spacetime region for each of the worlds at which it exists (but the regions themselves are each confined to a single world). Though McDaniel himself neither accepts nor rejects MRO, he takes it to be a serious contender as a theory of de re modality and possible worlds. ${ }^{9}$

characterization focuses on spatiotemporal examples, it is not obvious that the only entities that can be exactly occupied are spacetime regions. Perhaps there are such things as (nonspatiotemporal) argument places in universals. If so, we may want to say that they are exactly occupied by various things. For skepticism about the intelligibility of 'exactly occupies' (and hence of the multi-location thesis), see Parsons (2008). For a defense, see Hudson (2008).

${ }^{5}$ Hudson (2001: 61-71) endorses 3P, McDaniel (2004) claims that the defender of 'modal realism with overlap' should endorse it, and Donnelly (forthcoming) claims that multi-locationists more generally should endorse 3P (or some very similar thesis stated a bit differently).

${ }^{6}$ I will ignore a fourth view about the adicity of $\operatorname{parthood}_{\mathrm{m}}$ : viz., that it is a 'multigrade' or 'variably polyadic' relation, perhaps one that can hold between two objects (the 'part' and the 'whole') and various numbers of 'indices' such as times, places, spacetime regions, moments of proper or personal time, possible worlds, sortals, etc. I will assume that this is an answer of last resort to the Adicity Question.

${ }^{7}$ Endurantism, roughly, is the view that material objects persist not by having different temporal parts at different times but by being wholly present at each time at which they exist.

${ }^{8}$ Perdurantism, roughly, is the view that material objects persist by having different temporal parts at different times. This contrasts both with endurantism and with the 'stage view' (Sider 2001) according to which ordinary material objects are instantaneous stages that persist by bearing a temporal counterpart relation to other stages located at other times.

${ }^{9}$ Some philosophers deny that material objects are multi-located but apparently accept (or, in the case of Lewis, remain agnostic about) multi-location for entities in other categories, such as universals (Newman (2002), Armstrong (1989), Lewis (1983, 1986a)) or tropes (Campbell (1981: 487), Ehring (1997: chs. 4 and $5)$ ). 
Multi-location, then, is a 'big tent' that includes a wide range of views about material objects. As I will understand it, however, the doctrine builds in quite specific and controversial assumptions about spacetime. In particular, it incorporates a form of spacetime substantivalism. ${ }^{10}$ On this view, spacetime points and regions exist in their own right and are not to be reduced to things or events standing in spatiotemporal relations. Spacetime points are taken to be instantaneous, spatially unextended concrete particulars, and a spacetime region is taken to be any non-empty collection of such points. (Multi-location is neutral as to whether these 'collections' are sets that have their points as members or sums that have their points as parts.) Given this form of substantivalism, the best candidates for being instants of time are spacetime regions of a certain sort - viz., regions that are temporally unextended, so that any two points in such a region are simultaneous or spacelike separated, and maximal, i.e., not subregions of other temporally unextended regions. I will call such regions global time-slices.

So much for preliminaries. The plan for the rest of the paper is as follows. In section 2 I

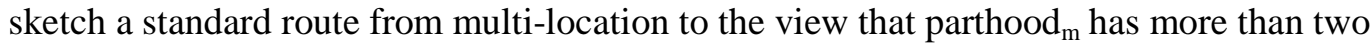
argument places. In section 3 I mount a detailed case against 3P, the view that parthood $\mathrm{m}_{\mathrm{m}}$ is a three-place relation. In section 4 show that if we shift to the view that parthood $\mathrm{m}_{\mathrm{m}}$ is four-place, we can avoid the problems facing $3 \mathrm{P}$, and I suggest that we do not face any comparably serious new problems. Finally, in section 5, I address some questions about how to construct a formal theory of parthood $\mathrm{m}_{\mathrm{m}}$ on the assumption that it is a four-place relation.

\section{From Multi-Location to the Denial of Absolutism}

Let us say that a spacetime region $\mathrm{R}$ is a location of an object $\mathrm{O}$ just in case $\mathrm{O}$ exactly occupies $\mathrm{R}$. To accept multi-location is to hold that at least some material objects have multiple locations. For those who endorse this view, it is natural to think that a multi-located object could exhibit a robust form of mereological variation: intuitively, it could be entirely made up of one collection of parts at one of its locations, while being entirely made up of a different collection of parts at another of its locations. Indeed, so far as I know, all actual multi-locationists do in fact embrace this sort of mereological variation. I will assume that if one takes on these commitments, then one should reject Absolutism. ${ }^{11}$ I take this assumption to be quite widely held, ${ }^{12}$ typically on the basis of something like the following line of thought.

Suppose that material object $\mathrm{O}$ exactly occupies region $\mathrm{R} 1$, and that a different material object, $\mathrm{P}$, exactly occupies some proper subregion of $\mathrm{R} 1$. Then, in the absence of any considerations to the contrary, this makes it plausible that $\mathrm{P}$ bears a fundamental parthood relation to $\mathrm{O}$ (together perhaps with some region or regions). ${ }^{13}$ That is, this makes it plausible that $\mathrm{P}$ is a

\footnotetext{
${ }^{10}$ One might wish to combine the view that material objects are (in some sense) multi-located with a relationist theory of spacetime, according to which there are material objects and events standing in various spatiotemporal relations, but there are no spacetime points or regions. Perhaps one could hold that some material objects are multi-located in the sense of being at a spatial or temporal distance from themselves. Such a view does not count as a form of multi-location, as I will be using that term, and I will not consider the view any further here. Thanks to Kris McDaniel.

${ }^{11}$ See Donnelly (forthcoming) for more on this issue.

${ }^{12}$ One potential exception is Sattig (2006). Sattig endorses multi-location and mereological variation between locations, but I do not know whether he believes that there is a fundamental parthood relation that can hold between material objects.

${ }^{13}$ The main alternative is to claim that $\mathrm{P}$ merely bears some non-fundamental parthood relation to $\mathrm{O}$, some relation that is defined in terms of a more natural parthood relation. Consider, e.g., the standard perdurantist treatment of the following case: an oxygen molecule enters my body, becomes 'caught up in my life' for a while, then leaves my body. Perdurantists typically hold that each object exactly occupies just one region its entire 'spacetime path.' Since the oxygen molecule's path overlaps mine but is not a subregion of mine, the standard perdurantist will say that the molecule does not exactly occupy any subregion of any region that I exactly occupy. Given this view, we should deny that the molecule bears parthood $\mathrm{m}_{\mathrm{m}}$ to me
} 
part $_{m}$ of $\mathrm{O}$, perhaps at some region or regions. Further, suppose that $\mathrm{O}$ also exactly occupies some spacetime region $\mathrm{R} 2$ distinct from $\mathrm{R} 1$, but that $\mathrm{P}$ does not exactly occupy any subregion of $\mathrm{R} 2$. Then, again absent any considerations to the contrary, this makes it plausible that $\mathrm{P}$ bears the negation of that same parthood relation to $\mathrm{O}$ (together perhaps with some region or regions). In other words, this makes it plausible that $\mathrm{P}$ is a non-part $\mathrm{m}_{\mathrm{m}}$ of $\mathrm{O}$, perhaps at some region or regions.

Now, with all this in place, suppose that parthood ${ }_{m}$ is two-place. Then the "perhaps at some region or regions' clauses above never come into play, and we face pressure to say that $\mathrm{P}$ is both a part $\mathrm{m}_{\mathrm{m}}$ of $\mathrm{O}$ (simpliciter) and a non-part $\mathrm{m}_{\mathrm{m}}$ of $\mathrm{O}$ (simpliciter), ${ }^{14}$ which is absurd. On the other hand, if parthood ${ }_{m}$ has an extra argument place, we face no pressure to say this. Instead we can fall back on those 'perhaps at some region or regions' clauses: we can say that $\mathrm{P}$ is a part $_{\mathrm{m}}$ of $\mathrm{O}$ at one region and a non-part $\mathrm{m}_{\mathrm{m}}$ of $\mathrm{O}$ at a different region. Thus, if we think that material objects are multi-located and vary mereologically between locations, this will give us a quite powerful reason to postulate at least one extra argument place in parthood $\mathrm{m}_{\mathrm{m}}$.

\section{Problems for Three-Place Parthood}

If parthood $\mathrm{m}$ is a three-place relation, then one question that arises immediately is what I will call the Restriction Question: what conditions does a spacetime region $\mathrm{R}$ have to meet in order for a material object $\mathrm{x}$ to be a part $\mathrm{m}$ of a material object y at $\mathrm{R}$ ? Must $\mathrm{R}$ be a maximal spatiotemporally interrelated region ${ }^{15}$ - i.e., a 'complete spacetime'? Must $\mathrm{R}$ be a global time-slice of a spacetime roughly, an instant? Must $\mathrm{R}$ be a location of $\mathrm{x}$ ? A location of $\mathrm{y}$ ? Must $\mathrm{R}$ overlap some location of one or both of them? I will argue that the Restriction Question gives rise to serious problems for $3 \mathrm{P}$, and that $4 \mathrm{P}$ avoids these problems entirely.

I will begin by describing a very simple case of parthood $\mathrm{m}_{\mathrm{m}}$. Concerning this case, I will ask: relative to which region or regions does parthood $_{\mathrm{m}}$ hold? I examine what I take to be the best answers available to the defender of 3P, and I argue that each of them has major drawbacks. I then show that if we reject 3P in favor of 4P, we can answer the Restriction Question in a way that does not give rise to any comparably serious objections.

Here is the case, which I will call Case 1. Material objects a and b are each "monolocated': each of them exactly occupies just a single spacetime region. Object a's location is the temporally unextended region $\mathrm{Ra}$, and b's location is the temporally unextended region $\mathrm{Rb}$,

(anywhere). At best, it bears some non-fundamental parthood relation to me - e.g., a time-relative parthood relation defined in terms of parthood $\mathrm{m}_{\mathrm{m}}$ as follows:

Part-at-t $\quad x$ is part of $y$ at $t=d f$. (i) $t$ is an instant of time and (ii) $x$ 's instantaneous temporal part at $\mathrm{t}$ is a part $_{\mathrm{m}}$ of $\mathrm{y}$ 's instantaneous temporal part at $\mathrm{t}$.

Temporal part $\quad x$ is an instantaneous temporal part at $t$ of $y=d f$. (i) $t$ is an instant of time, (ii) $x$ exists at $t$ but only at $t$, (iii) $x$ is a part $\mathrm{m}_{\mathrm{m}}$ of $\mathrm{y}$, and (iv) every $\operatorname{part}_{\mathrm{m}}$ of $\mathrm{y}$ that exists at $\mathrm{t}$ has a part $_{\mathrm{m}}$ in common with $\mathrm{x}$.

This allows the perdurantist to say that the oxygen molecule is a part of me at certain times despite not bearing any fundamental parthood relation to me. (This strategy is developed by Sider 2001.) This seems to be the best option for a pair of material objects neither of which exactly occupies any subregion of any region exactly occupied by the other. But given the fact that our object $\mathrm{P}$ does exactly occupy a proper subregion of a region that $\mathrm{O}$ exactly occupies, $\mathrm{P}$ and $\mathrm{O}$ seem to be especially good candidates for instantiating a fundamental parthood relation.

${ }^{14}$ Even if parthood $\mathrm{m}$ is two-place, this conclusion can be avoided if some 'relativizing' theory is true of the instantiation relation, so that it has additional argument places for times or spacetime regions. (See Haslanger (2003) for a survey of 'relativizing' options vis-à-vis change with respect to apparently monadic intrinsic properties.) This alternative is much in the spirit of non-Absolutist theories of parthood $\mathrm{m}_{\mathrm{m}}$. But the alternative theory makes it harder to set out a formal theory of parthood $\mathrm{m}_{\mathrm{m}}$ than it is in the context of relativizing theories that put the extra $\operatorname{argument}_{\text {place(s) into }}$ parthood $_{\mathrm{m}}$ itself. See section 4.

${ }^{15}$ To say that $\mathrm{R}$ is a maximal spatiotemporally interrelated spacetime region is to say that (i) $\mathrm{R}$ is a spacetime region, (ii) each point in $\mathrm{R}$ is spatiotemporally related to each other point in $\mathrm{R}$, and (iii) no point that is not in $\mathrm{R}$ is spatiotemporally related to any point in $\mathrm{R}$. 
which does not overlap with Ra. Material object $\mathrm{C}$ is also mono-located: it exactly occupies $\mathrm{Rc}$, which is the sum or union of $\mathrm{Ra}$ and $\mathrm{Rb}$. Intuitively, we should think of $\mathrm{a}$ and $\mathrm{b}$ as being nonoverlapping proper parts of $\mathrm{c}$, and we should think of $\mathrm{c}$ as having no parts that are disjoint from each of $a$ and $b$.

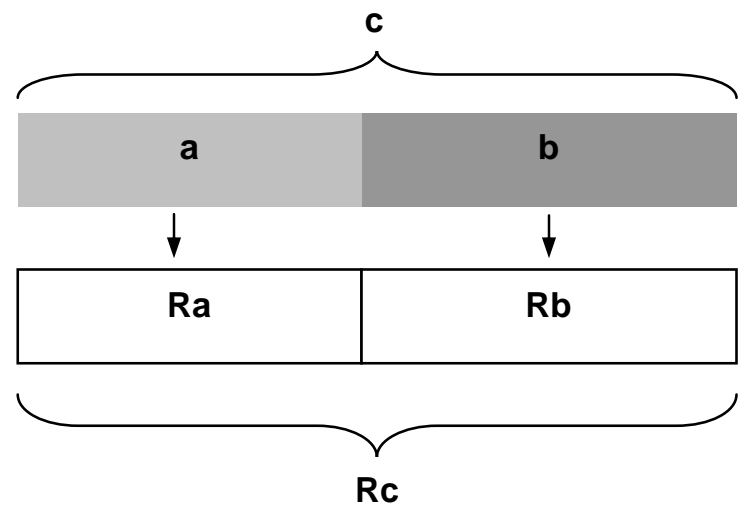

In Case 1, it is plausible that a is a partm of c 'exactly once'. It seems that there is just one 'instance' of parthood $_{m}$ involving $a$ and $c$.

Figure 1

To avoid prejudging the main question, however, we make no stipulations as to where $a$ or $b$ are parts $_{\mathrm{m}}$ of $\mathrm{c}$. Instead, we can consider a list of candidates for being regions at which a is a part $\mathrm{m}_{\mathrm{m}}$ of c. (For simplicity we ignore b.)
Ra:
a's location.
Rc: c's location.
Rmax: a maximal spatiotemporally interrelated region (a 'complete spacetime') that has $\mathrm{Rc}$ as a proper subregion.
Rblob: $\quad$ a four-dimensional region that has $\mathrm{Rc}$ as a proper subregion and $\mathrm{Rmax}$ as a proper superregion.
Rslice: a global time-slice that has $\mathrm{Rc}$ as a proper subregion.
Rslice-: $\quad$ an instantaneous region that has $\mathrm{Rc}$ as a proper subregion and Rslice as a proper superregion.
Rchunk: a global 'time-chunk' of a certain temporal thickness that has Rslice as a proper subregion and Rmax as a proper superregion.
$\mathrm{Ra}+\mathrm{a} \quad \quad \quad \quad \quad$ region that is a proper superregion of $\mathrm{Ra}$ and a proper subregion of Rc.
Ra-: $\quad$ a proper subregion of Ra.
Rc-: $\quad$ a proper subregion of Rc that does not overlap Ra.
Re: $\quad$ a subregion of Rmax that does not overlap Rc.

At which of these regions, if any, is a a part $\mathrm{m}_{\mathrm{m}}$ of $\mathrm{c}$ ? Two types of answers are available to proponents of 3P: pluralist answers, according to which $\mathrm{a}$ is a part $\mathrm{m}_{\mathrm{m}}$ of $\mathrm{c}$ at more than one of the given regions, and non-pluralist answers, according to which $\mathrm{a}$ is a $\operatorname{part}_{\mathrm{m}}$ of $\mathrm{c}$ at no more than one of the given regions.

\subsection{Pluralist Answers}

Pluralist answers are vulnerable to a simple but compelling objection. ${ }^{16}$ Intuitively, a is a part ${ }_{\mathrm{m}}$ of $c$ 'only once'. Relatedly, there seems to be just one 'case' or 'instance' of parthood ${ }_{m}$ involving a

\footnotetext{
${ }^{16}$ As I note later, these answers are also vulnerable to problems arising from the 'two case intuition' to be discussed in 3.2.3.
} 
and c. But if parthood ${ }_{\mathrm{m}}$ were three-place and a were a partm of $\mathrm{C}$ at multiple regions, then there

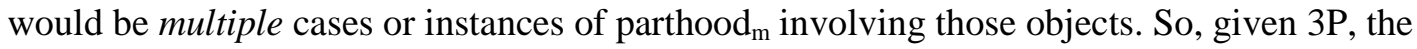
pluralist answers are false. It will be convenient to set this out in numbered form:

P1 If parthood ${ }_{m}$ is three-place and $a$ is a part ${ }_{m}$ of $c$ at more than one of the given regions, then there is more than one instance of parthood $_{\mathrm{m}}$ involving $\mathrm{a}$ and $\mathrm{c}$.

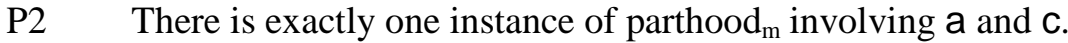

C So, if parthood $_{m}$ is three-place, then a is a part $\mathrm{m}_{\mathrm{m}}$ of $\mathrm{C}$ at no more than one of the given regions.

Let me begin by saying a bit more about P1. I assume that, regardless of what one ultimately wants to say about the metaphysics of property instances (and relation instances), ${ }^{17}$ and regardless of one's favored answer to the Adicity Question or the Restriction Question, one can agree that the number of instances of parthood ${ }_{m}$ is equal to the number of ordered $n$-tuples whose members instantiate parthood $\mathrm{d}_{\mathrm{m}}$ (in the order given by the n-tuple). ${ }^{18}$ More specifically, I assume that for any number, \#, there are \# instances of parthood $\mathrm{d}_{\mathrm{m}}$ involving a and $\mathrm{c}$ just in case there are \# $\mathrm{n}$-tuples containing $\mathrm{a}$ and $\mathrm{c}$ whose members instantiate parthood $\mathrm{m}_{\mathrm{m}}$ (in the order given by the $\mathrm{n}$-tuple).

Now, if parthood $\mathrm{m}_{\mathrm{m}}$ were three-place, and a were a part $\mathrm{m}_{\mathrm{m}}$ of $\mathrm{C}$ at multiple regions - say, at exactly two distinct regions, $r$ and $r^{*}$-then there would be multiple ordered triples containing a and $\mathrm{c}$ whose members instantiate parthood $_{\mathrm{m}}$ (in the order given by the triple): namely, $\langle\mathrm{a}, \mathrm{c}, \mathrm{r}\rangle$

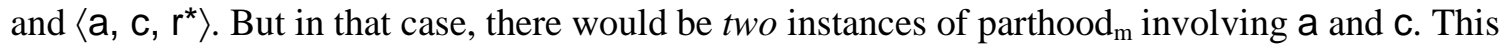
confirms $\mathrm{P} 1$.

We can turn now to P2, which I will call the single case intuition. It says that we have just a single instance of parthood ${ }_{\mathrm{m}}$ involving a and $\mathrm{C}$. This claim can be motivated in at least three ways. First and most importantly, it should seem highly plausible on its own. It is not the sort of thing that anyone would even think to question had it not been used as a premise in an argument. Suppose that, in another context, we were given the set-up of Case 1, together with its depiction

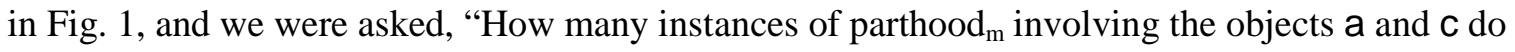
we have in this case?" We would not hesitate to answer, "One," or so I conjecture.

Moreover, if the set-up of the case had been different in certain ways, we would have had different intuitions about how many such instances the case contains. Suppose, e.g., that $c$ had two nonoverlapping locations, and that each of these contained a location of a as a subregion. (See Fig. 2.) Then (other things being equal) it would seem appropriate to say that a was a part $\mathrm{m}_{\mathrm{m}}$ of c 'twice' - once above and once below - and that, correspondingly, there were two instances

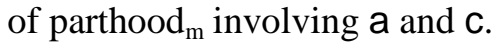

\footnotetext{
${ }^{17}$ One might hold that an instance of an $\mathrm{n}$-adic relation $\mathrm{R}$ is merely an ordered pair $\left\langle\mathrm{R},\left\langle\mathrm{o}_{1}, \ldots, \mathrm{o}_{\mathrm{n}}\right\rangle\right\rangle$ such that the members of $\left\langle\mathrm{o}_{1}, \ldots, \mathrm{o}_{\mathrm{n}}\right\rangle$ instantiate $\mathrm{R}$ in the given order.

${ }^{18}$ One can accept this claim without accepting a generalized variant of it to the effect that for any relation $\mathrm{R}$, the number of instances of $\mathrm{R}=$ the number of $\mathrm{n}$-tuples whose members instantiate $\mathrm{R}$ (in the given order). One might think that symmetric relations, such as being two feet away from, are counterexamples to the more general principle, for one might think that in a situation in which a is two feet from $b$, there are two ordered pairs, $\langle a, b\rangle$ and $\langle\mathrm{b}$, a $\rangle$, whose members instantiate the relation in the given order, but one might find it counterintuitive to say that in such a situation we have two instances of being two feet away from. Nevertheless, since parthood ${ }_{m}$ is not symmetric, this style of case does nothing to cast doubt on the original claim stated in the main text.
} 

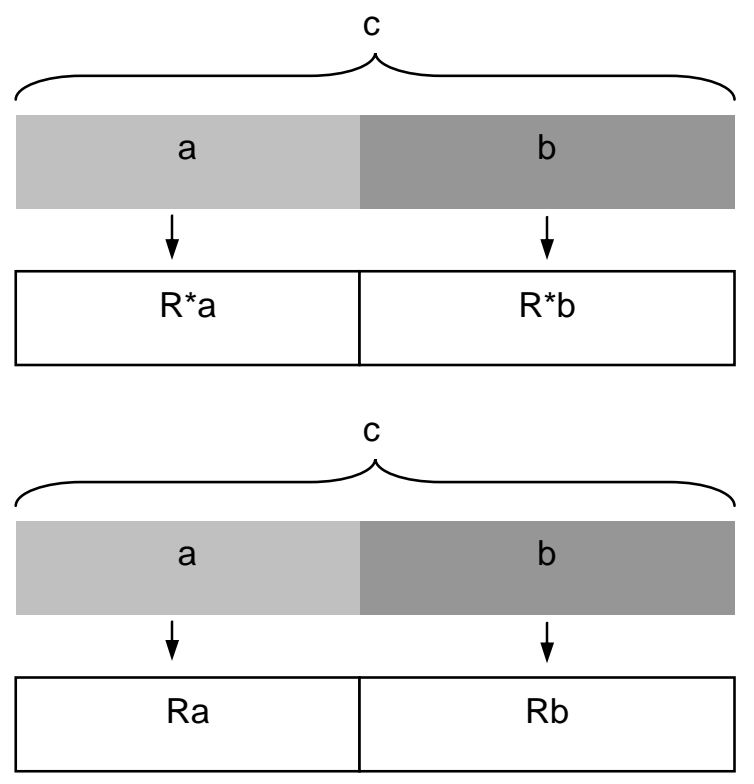

In this variant of Case 1, it is plausible that $a$ is a part $m$ of $c$ 'twice'. It seems that there are two 'instances' of parthood $\mathrm{m}_{\mathrm{m}}$ involving $\mathrm{a}$ and $\mathrm{c}$, one that is associated with the lower portion of the diagram, and another that is associated with the upper portion of the diagram.

Figure 2

But as things stand in Case 1, c has just one location, and a has just one location (a subregion of c's). Someone who was willing to speak of 'occurrences' of material objects would say that we have just one occurrence of $c$ and just one occurrence of $a$, and that the latter is a part simpliciter of the former. In these circumstances, it is overwhelmingly plausible that $a$ is part $_{\mathrm{m}}$ of $\mathrm{c}$ just once, and that there is just one instance of parthood ${ }_{m}$ involving the two objects.

A second line of motivation for the single case intuition looks to the verdicts of Absolutism. The thought here is that Absolutism, in virtue of its simplicity and its pedigree ${ }^{19}$, has a kind of default status, so that if certain pieces of data (e.g., multi-location together with mereological variation between locations) force us to reject Absolutism in favor of $3 \mathrm{P}$ or $4 \mathrm{P}$, then we should depart from Absolutism only as much as is necessary to accommodate the data in question. In particular, we should strive to make our non-Absolutist theory of parthood $\mathrm{m}_{\mathrm{m}}$ resemble Absolutism as closely as possible in important respects (while still accommodating the data). One important respect in which two theories of parthood $_{m}$ can agree concerns their verdicts on the single case intuition.

Absolutism delivers a clear verdict in favor of that intuition. According to Absolutism, a and $\mathrm{c}$ belong to just one ordered $\mathrm{n}$-tuple whose members instantiate parthoodm (in the order specified by the n-tuple) - namely, the ordered pair $\langle a, c\rangle$. Absolutists, therefore, will say that in

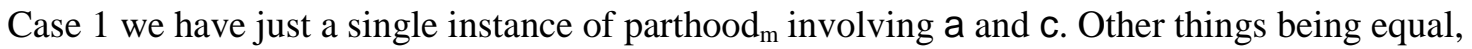
then, non-Absolutists should prefer a theory that lets them say this as well.

A third motivation for the single case intuition appeals to considerations of parsimony. For properties and relations as fundamental as parthood ${ }_{m}$, we should seek to avoid redundancy: other things being equal, we should hold that these properties and relations are instantiated only as many times as is needed to fully account for how things are. It seems clear that in Case 1, we

\footnotetext{
${ }^{19}$ Traditional formal theories of the part-whole relation employ a two-place parthood predicate. See Simons (1987) for a survey. Contemporary perdurantists (with the exception of Hudson (2001)) all speak as though they accept Absolutism, as do contemporary presentists (who hold that only what is present exists at all). Moreover, even some multi-locationists (van Inwagen 1990) find it convenient to work under the pretense that parthood $_{\mathrm{m}}$ is two-place.
} 
can fully account for how things are - and in particular, we can fully account for the mereological relationship between $\mathrm{a}$ and $\mathrm{c}$ - without claiming that $\mathrm{a}$ and $\mathrm{c}$ instantiate parthood $\mathrm{d}_{\mathrm{m}}$ many times over (at multiple regions). On the contrary, that claim would result in something analogous to an over-determination of their mereological relationship; it 'over-characterizes' this relationship. To avoid this sort of redundancy, we should embrace the single case intuition.

It is worth noting that the single case intuition is perfectly consistent with the view that there are nonfundamental parthood relations that hold more than once between a and c. Consider the relation defined as follows:

D3 $\mathrm{x}$ is a part of $\mathrm{y}$ within $\mathrm{R}=\mathrm{df}$. there is some spacetime region $\mathrm{R}^{*}$ such that $\mathrm{x}$ is a partm of $\mathrm{y}$ at $\mathrm{R}^{*}$ and $\mathrm{R}^{*}$ is a subregion of $\mathrm{R}$.

If $a$ is a part $m$ of $c$ at a region $R^{*}$, then $a$ is a part of $c$ within every superregion of $R^{*}$. So unless $\mathrm{R}^{*}$ has no proper superregions, the relation of part-within will hold between a and $\mathrm{c}$ many times over. But this does nothing to undermine the thought that the fundamental parthood relation for material objects, parthood $\mathrm{m}_{\mathrm{m}}$, holds between a and $\mathrm{c}$ just once.

In sum, then, the situation is this. In order to respect the single case intuition, the friend of 3P must deny that $\mathrm{a}$ is a $\operatorname{part}_{\mathrm{m}}$ of $\mathrm{C}$ at more than one region: he should reject the pluralist answers to our question about $\mathrm{a}$ and $\mathrm{c}^{20}$

\subsection{Non-pluralist Answers}

Non-pluralist answers all say that $\mathrm{a}$ is a $\operatorname{part}_{\mathrm{m}}$ of $\mathrm{c}$ at no more than one of the regions listed earlier. Interestingly, the single case intuition helps us to dispense with several of these answers as well.

For example, we can immediately reject the suggestion that $\mathrm{a}$ is not a $\operatorname{part}_{\mathrm{m}}$ of $\mathrm{C}$ at any of those regions. Given the single case intuition and 3P, a must be a part $\mathrm{m}_{\mathrm{m}}$ of $\mathrm{C}$ at some region. But surely we haven't excluded all of the best candidates from our list! If $a$ is $\operatorname{part}_{\mathrm{m}}$ of $\mathrm{c}$ at any region, surely it is a part $\mathrm{m}_{\mathrm{m}}$ of $\mathrm{c}$ at some region on the list.

Likewise, we can reject the view that $a$ is a part $_{m}$ of $c$ at exactly one of the following: Rblob, Rchunk, Rslice-, Ra+, Ra-, Rc-, or Re. Suppose, for example, that a is a part $_{\mathrm{m}}$ of $\mathrm{c}$ at

\footnotetext{
${ }^{20}$ Some multi-locationists may be tempted to deny the possibility of Case 1 as a way of resisting my argument against the pluralist answers. Consider first the endurantist who denies the possibility of instantaneous material objects, such as a and b. Any material object, he says, must have a temporally extended path and must be multi-located within that path. In response, I say that whatever (slight) plausibility this may have as applied to material simples, it has even less as applied to composite material objects. Suppose that a itself is simple and has a temporally extended path whose final slice is Ra, and that $\mathrm{b}$ is also simple and has a temporally extended path whose first slice is Rb. Thus $a$ and $b$ coexist for just a single instant, and at that instant they compose the instantaneous composite object, C. As before, we have the intuition that $\mathrm{a}$ is a partm of $\mathrm{c}$ just once.

Perhaps some multi-locationists will go so far as to deny the possibility of instantaneous composite material objects as well. But then we can note that even if $\mathrm{a}$ is a part of $\mathrm{c}$ throughout some extended interval (so that $\mathrm{a}$ is part $_{\mathrm{m}}$ of $\mathrm{c}$ at different regions associated with different global time-slices),

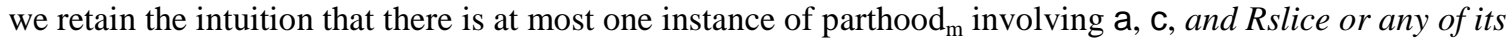
subregions. So, given 3P, we should not say that a is part $\mathrm{m}_{\mathrm{m}}$ of $\mathrm{C}$ at each of the following: Ra, Rc, Rslice-, and Rslice. Rather, given 3P, we should say that $\mathrm{a}$ is $\operatorname{part}_{\mathrm{m}}$ of $\mathrm{C}$ at no more than one of those regions. Similarly, perhaps some defenders of Modal Realism with Overlap will deny the possibility of material objects that exist in just one concrete possible world. But even if we grant that a and $c$ have other locations in other worlds, we retain the intuition that $\mathrm{a}$ is $\operatorname{part}_{\mathrm{m}}$ of $\mathrm{c}$ just once in the original world: i.e., there is at most one instance of parthood ${ }_{\mathrm{m}}$ involving $\mathrm{a}, \mathrm{c}$, and Rmax or any of its subregions. (According to MRO as McDaniel presents it, spacetime regions, unlike material objects, are worldbound.) Together with $3 \mathrm{P}$, this generates pressure to say that $\mathrm{a}$ is a $\mathrm{part}_{\mathrm{m}}$ of $\mathrm{C}$ at no more than one of these regions.
} 
Rblob. Then, since there is nothing special about that region, presumably a must also be a part ${ }_{m}$ of $\mathrm{C}$ at all such regions - i.e., at all four-dimensional regions that are both proper superregions of $R c$ and proper subregions of Rmax. To say that $a$ is a part $t_{m}$ of $c$ at Rblob but not at any of these other regions like it would be unacceptably arbitrary. Relations as metaphysically basic as parthood $_{m}$ are just not that haphazard. Given the single case intuition, however, we cannot say that $\mathrm{a}$ is a part $\mathrm{m}$ of $\mathrm{C}$ at all of the many regions like Rblob. So we should deny that $\mathrm{a}$ is a $\operatorname{part}_{\mathrm{m}}$ of $\mathrm{C}$ at Rblob. Parallel arguments can be given to show that $\mathrm{a}$ is not a $\operatorname{part}_{\mathrm{m}}$ of $\mathrm{C}$ at Rchunk, Rslice-, Ra-, Rc-, or Re. None of these regions can be plausibly said to be the only region at which a is a part $_{\mathrm{m}}$ of c. This leaves us with four remaining candidates: Rmax, Rslice, Ra, and Rc.

\subsubsection{The Spacetime Principle}

We can begin by considering the Rmax view, according to which a is a part $\mathrm{m}_{\mathrm{m}}$ of $\mathrm{C}$ at $\mathrm{Rmax}$ and only there. (Rmax, recall, is the complete spacetime in which a and $c$ are embedded.) This view is associated with the following general principle:

The Spacetime Principle

$$
\begin{aligned}
& \text { Necessarily, for any material objects } \mathrm{x} \text { and } \mathrm{y} \text { and any } \mathrm{z} \text {, } \\
& \text { if } \mathrm{x} \text { is a part } \mathrm{m} \text { of } \mathrm{y} \text { at } \mathrm{z} \text {, then } \mathrm{z} \text { is a maximal } \\
& \text { spatiotemporally interrelated spacetime region (a } \\
& \text { 'complete spacetime') that includes a location of } \mathrm{x} \text { and a } \\
& \text { location of y as subregions. }
\end{aligned}
$$

I will assume that if the Rmax view is true, then the Spacetime Principle is true as well. Although this assumption could be questioned, it will appeal to those who agree that properties and relations as metaphysically basic as parthood $\mathrm{d}_{\mathrm{m}}$ are not haphazard. Parthood $\mathrm{d}_{\mathrm{m}}$, for example, does not hold relative to a complete spacetime in one case and relative to an arbitrarily selected proper subregion of a spacetime in another, otherwise similar case. Rather, properties and relations as basic as parthood ${ }_{m}$ are governed by relatively simple general rules and have their 'core features', such as their adicities, essentially. I take it that if $\operatorname{parthood}_{m}$ is in fact governed by the Spacetime Principle, then this is one of its core features. (Likewise for the competing general principles that I discuss.)

The Spacetime Principle might appeal to a certain subset of those philosophers who endorse MRO. As I mentioned earlier, MRO is a form of realism about possible worlds according to which (i) possible worlds are concrete entities (specifically, they are 'complete spacetimes') and (ii) at least some material objects are 'wholly present' in more than one world, where being wholly present in a given world is understood as exactly occupying some subregion of that world. Friends of MRO will disagree amongst themselves as to whether material objects ever exactly occupy multiple subregions of a given world. Those who endorse multi-location within worlds will reject the Spacetime Principle, ${ }^{22}$ but those who reject multi-location within worlds may initially be more sympathetic to that principle. ${ }^{23}$

\footnotetext{
${ }^{21}$ To this we might plausibly add some further clause to the effect that $\mathrm{x}$ 's location in $\mathrm{z}$ is a subregion of y's location in z. It will be unclear how this further clause should be specified if one believes that some objects are multi-located within a single spacetime, but as I note below, anyone who believes this is unlikely to accept the Spacetime Principle. See Donnelly (forthcoming) for a discussion of related questions.

22 These philosophers will presumably want to say that material objects often vary mereologically between locations within a single spacetime - e.g., that at one of my locations within this spacetime, I am made up of one collection of particles, and at another of my locations within this same spacetime, I am made up of a different collection of particles. On this view, there will be many true sentences of the form, 'Material object $\mathrm{p}$ is a part $\mathrm{m}_{\mathrm{m}}$ of material object o at region $\mathrm{r} 1$ but not at region $\mathrm{r} 2$, although $\mathrm{r} 1$ and $\mathrm{r} 2$ are both proper subregions of the same spacetime'. This obviously conflicts with the Spacetime Principle.

${ }^{23}$ According to them, mereological variation between locations never occurs within a single spacetime. If I

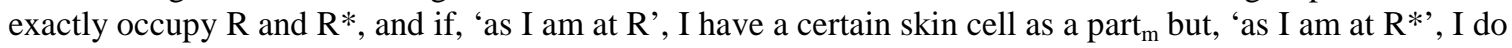


The Rmax view and the Spacetime Principle mesh well with the single case intuition, and thus they avoid the problems facing the previous answers that we have considered. Together with the set-up of Case 1, the Rmax view entails that there is just one region at which a is a part $\mathrm{m}_{\mathrm{m}}$ of $\mathrm{c}$, and hence that $\mathrm{a}$ is a part $\mathrm{m}$ of $\mathrm{c}$ 'just once'. Moreover, there is nothing arbitrary about a's being a part $\mathrm{m}_{\mathrm{m}}$ of $\mathrm{C}$ only at Rmax. After all, Rmax is quite special as far as a and $\mathrm{C}$ are concerned: it is the only complete spacetime that contains either of them.

Still, the Spacetime Principle has a drawback. To state the argument against this principle, I will need to invoke some technical terminology. I take it that the notion of intrinsicness, as applied to properties, is familiar and well understood (even if its precise definition remains elusive). Roughly, a property $\mathrm{P}$ is intrinsic just in case whether or not an object $\mathrm{O}$ has $\mathrm{P}$ depends only on what $\mathrm{O}$ is like in itself and is independent of how $\mathrm{O}$ is related to things separate from itself. Or, in different terms, a property is intrinsic iff it cannot differ between duplicates.

It is also fairly easy to get a grip on a notion of intrinsicness for relations, although the terminology here is a bit less familiar. We can start with the notion of plural duplication. (I take this term from McDaniel 2008.) Intuitively, to say that the Xs and the Ys are plural duplicates is to say that the Xs match the Ys with respect to their intrinsic properties and internal arrangement, though not necessarily with respect to how they are related to outside things.

For example, suppose that Tom, Dick, and Harry are standing in a column, single-file, all facing North, and are arranged by increasing height, so that Tom, the shortest, is in front, and Harry, the tallest, is in the back, with each of them being exactly two feet away from Dick, who is in the middle. Further, suppose that Tom*, Dick*, and Harry* are intrinsic duplicates of Tom, Dick, and Harry, respectively, and are arranged in an exactly similar fashion with regard to their spatial and causal relations. Then Tom, Dick, and Harry are plural duplicates of Tom*, Dick*, and Harry*, even if the latter trio are, say, facing in a different direction, or nearer to a lake, than are the former trio.

If we help ourselves to the notion of an intrinsic property and to Lewis's notion of a perfectly natural relation (see note 2 ), then we can offer a more formal definition of plural duplication as follows:

D4 the Xs and the Ys are plural duplicates =df. there is a one-one correspondence between the Xs and the Ys that preserves intrinsic properties and perfectly natural relations - i.e., a bijective function $f$ such that (i) for any intrinsic property $\mathrm{P}$ and for any $\mathrm{x}$ among the $\mathrm{Xs}$, $\mathrm{x}$ instantiates $\mathrm{P}$ iff $\mathrm{f}(\mathrm{x})$ instantiates $\mathrm{P}$, and (ii) for any perfectly natural relation $\mathrm{R}$ and any ordered $n$-tuple $\left\langle\mathrm{x}_{1} \ldots \mathrm{x}_{\mathrm{n}}\right\rangle$ of the $X s, x_{1} \ldots x_{n}$ instantiate $R$ in that order iff $f\left(x_{1}\right) \ldots f\left(x_{n}\right)$ instantiate $R$ in that order.

With the notion of plural duplication in hand, I can define an intrinsic relation as one that cannot differ between pluralities that are plural duplicates. Thus, if the Xs and the Ys are plural

not have that cell as a part $\mathrm{m}_{\mathrm{m}}$, then these locations will be subregions of different spacetimes - say, $w$ and $\mathrm{w}^{*}$. This will allow us to account for any mereological variation between my locations by relativizing to spacetimes. We will be able to say: the cell is a part $\mathrm{m}_{\mathrm{m}}$ of me at spacetime $\mathrm{w}$ but is not a part $\mathrm{m}_{\mathrm{m}}$ of me at spacetime $\mathrm{w}^{*}$. Granted, mereological variation between locations is not the only sort of mereological variation (or apparent mereological variation) that these philosophers will need to account for. Such variation might also occur over time but within a single location. There is at least a sense in which, e.g., a certain hair, $\mathrm{h}$, is a part of me at $\mathrm{t}$ but not at $\mathrm{t}^{*}$, after it falls out. The MROists in question will see this as variation within a single location. On the assumption that they posit temporal parts, they can describe the case by saying that the $t$-part of $h$ is a part $t_{m}$ of my $t$-part at $w$ (this spacetime) while the $t^{*}$-part of $h$ is not a part $_{\mathrm{m}}$ of my $\mathrm{t}^{*}$-part at $\mathrm{w}$. 
duplicates, if $\mathrm{R}$ is an intrinsic relation, and if the Xs instantiate $\mathrm{R}$ (in some order), then the Ys instantiate $\mathrm{R}$ as well (in some order). I assume that being larger than and being two feet apart are both intrinsic relations and that having a common owner and being two feet apart and within three miles of a lake are extrinsic (non-intrinsic) relations. ${ }^{24}$

My argument against the Spacetime Principle hinges upon one crucial assumption: that parthood $_{\mathrm{m}}$, whatever its adicity, is an intrinsic relation. I will call this the intrinsicness intuition, and I will try to show that it cannot be plausibly combined with the package consisting of the Rmax view and the Spacetime Principle.

Let me begin by trying to motivate the intrinsicness intuition, albeit briefly. First, one might reasonably take parthood $\mathrm{m}_{\mathrm{m}}$, or indeed any fundamental parthood relation, to be a perfectly natural relation, in which case the definitions of plural duplication and 'intrinsic relation' given above will guarantee that parthood $\mathrm{d}_{\mathrm{m}}$ is intrinsic. Second, one might once again appeal to the principle that non-Absolutist theories of parthood $_{\mathrm{m}}$ should depart from Absolutism only as much as is necessary to accommodate the relevant data. In that case, since parthood $\mathrm{m}_{\mathrm{m}}$ is plausibly an intrinsic relation according to Absolutism, the friend of $3 \mathrm{P}$ or $4 \mathrm{P}$ should strive to accommodate the intrinsicness intuition too.

Third and most importantly, I take the intrinsicness intuition to be highly plausible on its own, even in the absence of any supporting argument. Suppose that material object $\mathrm{p}$ is a part $\mathrm{m}_{\mathrm{m}}$ of material object $\mathrm{o}$ at spacetime region $\mathrm{r}$, and that $\mathrm{p}^{*}, \mathrm{o}^{*}$, and $\mathrm{r}^{*}$ are plural duplicates of $\mathrm{p}, \mathrm{o}$, and $\mathrm{r}$ $\left(\right.$ respectively ${ }^{25}$ ). This means that $\mathrm{p}^{*}$ is a duplicate of $\mathrm{p}, \mathrm{o}^{*}$ is a duplicate of $\mathrm{o}$, and $\mathrm{r}^{*}$ is a duplicate of $\mathrm{r}$; and that $\mathrm{p}^{*}, \mathrm{o}^{*}$, and $\mathrm{r}^{*}$ are 'inter-related amongst themselves' in exactly the same manner as are $\mathrm{p}, \mathrm{o}$, and $\mathrm{r}$. Might it be that whereas $\mathrm{p}$ is a part $\mathrm{m}$ of $\mathrm{o}$ at $\mathrm{r}, \mathrm{p}^{*}$ is not a part $_{\mathrm{m}}$ of $\mathrm{o}^{*}$ at $\mathrm{r}^{*}$, despite all these similarities between the two trios? For those who find this as hard to believe as I do, the intrinsicness intuition will be compelling.

Now, to see why this intuition conflicts with the package consisting of the Rmax view and the Spacetime Principle, consider the trio of a, c, and Rc, the last of which is c's location. According to the Rmax view, the trio do not instantiate parthood $\mathrm{m}_{\mathrm{m}}$ : a is a part $\mathrm{m}_{\mathrm{m}}$ of $\mathrm{c}$ at $\mathrm{Rmax}$, not at Rc. But presumably there can be a trio, $a^{*}, c^{*}$, and $\mathrm{Rc}^{*}$, that are plural duplicates of $\mathrm{a}, \mathrm{c}$, and $\mathrm{Rc}$ (respectively), and that $d o$ instantiate parthood ${ }_{\mathrm{m}}$. Just suppose that $\mathrm{Rc}^{*}$ is a complete spacetime, but that $\mathrm{a}^{\star}, \mathrm{c}^{*}$, and $\mathrm{Rc}^{*}$ (and their internal arrangement) are as much like $\mathrm{a}, \mathrm{c}$, and $\mathrm{Rc}$ (and their internal arrangement) as is compatible with this difference. Thus $a^{*}$ is a duplicate of $a$, $\mathrm{c}^{*}$ is a duplicate of $\mathrm{c}$, and $\mathrm{Rc}^{*}$ is a duplicate of Rc. Moreover, the spatiotemporal and causal relations between $\mathrm{a}^{*}, \mathrm{c}^{*}$, and $\mathrm{Rc}^{*}$ match those between $\mathrm{a}, \mathrm{c}$, and Rc: the two trios are 'interrelated amongst themselves' in exactly the same manner.

The big difference between the two trios, of course, is that the original trio (of a, c, and $\mathrm{Rc}$ ) are embedded within a larger spacetime, so that $\mathrm{Rc}$ is a mere proper subregion of a spacetime, rather than being a complete spacetime in itself. The new trio (of $a^{*}, c^{*}$, and $R c^{*}$ ) do not find themselves embedded in a larger spacetime; $\mathrm{Rc}^{*}$ is not a subregion of any larger region. This difference, however, is clearly an extrinsic difference: it concerns only the ways in which the

\footnotetext{
${ }^{24}$ Lewis (1986a: 62) and offers a very closely related set of definitions. He defines an internal relation as one that 'supervenes on the intrinsic natures of its relata', and he defines an external relation as one that is not internal but nevertheless 'supervenes on the intrinsic nature of the composite of the relata taken together'. Bricker (1993: 274) systematizes the terminology (in a manner implicit in various things Lewis says) by defining an intrinsic relation as one that is either internal or external, and an extrinsic relation as one that is not intrinsic. Lewis takes being larger than to be internal (hence intrinsic, in Bricker's terminology), being two feet away from to be external (hence intrinsic, in Bricker's terminology), and having a common owner to be neither internal nor external (hence extrinsic, in Bricker's terminology).

${ }^{25}$ To say that $\mathrm{o}_{1} \ldots \mathrm{o}_{\mathrm{n}}$ are plural duplicates of $\mathrm{o}^{*}{ }_{1} \ldots \mathrm{o}_{\mathrm{n}}{ }_{\mathrm{n}}$ respectively is to say that the function $\mathrm{f}$ that pairs $\mathrm{o}_{1}$ with $\mathrm{o}^{*}{ }_{1}$ and $\ldots$ and $\mathrm{o}_{\mathrm{n}}$ with $\mathrm{o}^{*}{ }_{\mathrm{n}}$ preserves intrinsic properties and perfectly natural relations. Hence if $\mathrm{o}_{1} \ldots \mathrm{o}_{\mathrm{n}}$ are plural duplicates of $\mathrm{o}^{*}{ }_{1} \ldots *_{\mathrm{n}}$ respectively, and $\mathrm{R}$ is an intrinsic relation, and $\mathrm{o}_{1} \ldots \mathrm{o}_{\mathrm{n}}$ instantiate $\mathrm{R}$ in that order, then $\mathrm{o}_{1} \ldots \mathrm{o}_{\mathrm{n}}$ instantiate $\mathrm{R}$ in that order as well.
} 
members of a trio are related to things outside of themselves. Intrinsically, the two trios are just alike. They are plural duplicates.

Given the Spacetime Principle, we are forced to conclude that $a^{*}$ is a $\operatorname{part}_{\mathrm{m}}$ of $\mathrm{c}^{*}$ at $\mathrm{Rc}^{*}$ : after all, clearly $\mathrm{a}^{*}$ is a part $\mathrm{m}_{\mathrm{O}}$ of $\mathrm{c}^{*}$ at some region, and the only spacetime that has locations of $\mathrm{a}^{*}$ and $c^{*}$ as subregions is $R c^{*}$. So, if the Spacetime Principle and the Rmax view are true, then $a^{*}$ is a part ${ }_{m}$ of $c^{*}$ at $R c^{*}$, whereas a is not a part ${ }_{m}$ of $c$ at $R c$, despite the fact that the two trios are plural duplicates. But if parthood ${ }_{m}$ could differ in this way between plural duplicates, it would not be an intrinsic relation, contrary to the intrinsicness intuition. Call this style of argument a contraction argument. ${ }^{26}$

\subsubsection{The Time-Slice Principle}

Endurantists sometimes say that parthood $\mathrm{m}_{\mathrm{m}}$ is a 'time relative relation'. On one natural interpretation, this means that parthood $\mathrm{m}_{\mathrm{m}}$ is a three-place relation that can hold between two material objects and an instant of time. Some endurantists seem to accept this and, further, to endorse multi-location, according to which instants are spacetime regions of a special sort (global time slices).

With regard to Case 1, these endurantists will presumably want to endorse the Rslice view, according to which a is a part $\mathrm{m}_{\mathrm{m}}$ of $\mathrm{C}$ at exactly one region: a global time-slice that has $\mathrm{Rc}$ as a proper subregion. ${ }^{27}$ But it turns out that the Rslice view conflicts with the intrinsicness intuition just as badly as the Rmax view does. For the Rslice view, too, is vulnerable to a contraction argument. $^{28}$

As in the case of the Rmax view, I take it that the Rslice view is plausible only if accompanied by a corresponding general principle, which in this case would be

The Time-Slice Principle: Necessarily, for any material objects $\mathrm{x}$ and $\mathrm{y}$ and any $\mathrm{z}$, if $\mathrm{x}$ is a part $\mathrm{m}$ of $\mathrm{y}$ at $\mathrm{z}$ then $\mathrm{z}$ is a global time-slice that has a location of $\mathrm{x}$ and a location of $\mathrm{y}$ as subregions. ${ }^{29}$

As applied to the 'contracted' case of $\mathrm{a}^{*}, \mathrm{c}^{*}$, and $\mathrm{Rc}^{*}$ discussed earlier, the Time-Slice Principle will force us to conclude that $\mathrm{a}^{*}$ is a part $\mathrm{m}_{\mathrm{m}}$ of $\mathrm{c}^{*}$ at $\mathrm{Rc}^{*}$. When this conclusion is combined with the Rslice view and its claim that $\mathrm{a}$ is not $\mathrm{a} \mathrm{part}_{\mathrm{m}}$ of $\mathrm{c}$ at $\mathrm{Rc}$ (despite the fact that the trios are plural duplicates), we again get the unappealing result that parthood $_{\mathrm{m}}$ is not an intrinsic relation.

\footnotetext{
${ }^{26}$ A second argument against the Spacetime Principle arises from the possibility of what Parsons (2007) calls 'knuggy' worlds, worlds in which there are spacetime regions, and each of them has another such region as a proper superregion. Such worlds contain no maximal regions and, assuming that each point in such a world is spatiotemporally related to every other such point, they contain no maximal spatiotemporally interrelated regions - i.e., no 'complete spacetimes'. On the assumption that parthood $\mathrm{m}_{\mathrm{m}}$ can be instantiated within such worlds, the Spacetime Principle must be rejected.

${ }^{27}$ If the spacetime in Case 1 is relativistic, there might be many different global time-slices (i.e., many different maximal spacelike hypersurfaces) that have Rc as a subregion. Again, the single case intuition will put pressure on us to say that that $\mathrm{a}$ is a part $_{\mathrm{m}}$ of $\mathrm{c}$ at no more than one of these global time-slices.

${ }^{28}$ Some of these philosophers may have been tempted to say that parthood $\mathrm{m}_{\mathrm{m}}$ holds relative not merely to instants but also to temporally extended intervals. Given spacetime substantivalism, this would lead naturally to the view that $\mathrm{a}$ is a part $\mathrm{m}_{\mathrm{m}}$ of $\mathrm{c}$ not just at a global time-slice but also at the many global timechunks (e.g., Rchunk) that include their locations as subregions. This package conflicts with the single case intuition discussed in section 3.1. It is also vulnerable to a contraction argument, and so conflicts with the intrinsicness intuition, just as does the Time-Slice Principle + Rslice view package.

${ }^{29}$ We might add some clause to the effect that $\mathrm{x}$ 's location in $\mathrm{z}$ is a subregion of $\mathrm{y}$ 's location in $\mathrm{z}$. It becomes more difficult to specify the clause if we want to allow for the possibility that $\mathrm{x}$ and/or $\mathrm{y}$ have multiple locations within the same time-slice. See Donnelly (forthcoming) for more on this issue.
} 
This shows that the package consisting of the Rslice view and the Time-Slice Principle also conflicts with the intrinsicness intuition.

The Time-Slice Principle should be distinguished from

The Simple Instants Principle:

Necessarily, for any material objects $\mathrm{x}$ and $\mathrm{y}$ and any $\mathrm{z}$, if $\mathrm{x}$ is a $\operatorname{part}_{\mathrm{m}}$ of $\mathrm{y}$ at $\mathrm{z}$ then $\mathrm{z}$ is a simple, sui generis instant of time and $\mathrm{x}$ and $\mathrm{y}$ both exist at $\mathrm{z}$.

This principle is most plausible in the context of the view that (i) space is a (presumably threedimensional) manifold whose basic constituents are simple, enduring spatial points and (ii) time is a separate (presumably one-dimensional) manifold whose basic constituents are simple, nonpersisting instants. This view about space and time conflicts with multi-location.

The Simple Instants Principle (SIP) is apparently invulnerable to contraction arguments.

To apply such an argument to it, we would need to find 'plurally duplicate ordered triples', $\langle\mathrm{p}, \mathrm{o}$,

t $\rangle$ and $\left\langle\mathrm{p}^{*}, \mathrm{o}^{*}, \mathrm{t}^{*}\right\rangle$ only one of which passes SIP's test for parthoodm. These triples would need to be such that (i) $\mathrm{p}, \mathrm{o}, \mathrm{p}^{*}$, and $\mathrm{o}^{*}$ are all material objects, (ii) $\mathrm{t}$ is a simple instant and both $\mathrm{p}$ and $\mathrm{o}$ exist at $\mathrm{t}$, but (iii) either $\mathrm{t}^{*}$ is not a simple instant or either $\mathrm{p}^{*}$ or $\mathrm{o}^{*}$ fails to exist at $\mathrm{t}^{*}$. But since being a simple, sui generis instant is plausibly an intrinsic property, and since existing at is plausibly an intrinsic relation, it seems that we will not be able to find plurally duplicate ordered triples that differ in this way. (To say that the ordered n-tuples $\left\langle\mathrm{o}_{1} \ldots \mathrm{o}_{\mathrm{n}}\right\rangle$ and $\left\langle\mathrm{o}^{*}{ }_{1} \ldots \mathrm{o}_{\mathrm{n}}\right\rangle$ are 'plurally duplicate ordered n-tuples' is to say that the bijection $f$ that pairs the ith member of the first n-tuple with the ith member of the second preserves intrinsic properties and perfectly natural relations, and hence preserves intrinsic relations more generally.) ${ }^{30}$

So the doctrine of 'three-place, temporally relativized parthood ${ }_{\mathrm{m}}$ ' may be perfectly tenable in a context that includes simple, sui generis instants, but the doctrine becomes quite implausible when instants are treated merely as global time-slices, as they must be given multilocation. $^{31}$

\subsubsection{The Whole Location Principle and the Part Location Principle}

Return to the question, "At which region or regions is a a part $\mathrm{m}_{\mathrm{m}}$ of $\mathrm{c}$ ?" Two answers remain. According to the Ra view, a is a part $\mathrm{m}_{\mathrm{m}}$ of $\mathrm{C}$ at a's location, $\mathrm{Ra}$, and only there. According to the Rc view, a is a part $\mathrm{m}_{\mathrm{m}}$ of $\mathrm{C}$ at c's location, Rc, and only there. Each of these answers is associated with a general principle. The Ra view corresponds to

The Part Location Principle: $\quad$ Necessarily, for any material objects $\mathrm{x}$ and $\mathrm{y}$ and any $\mathrm{z}$, if $\mathrm{x}$ is a $\operatorname{part}_{\mathrm{m}}$ of $\mathrm{y}$ at $\mathrm{z}$, then $\mathrm{z}$ is a spacetime region and $x$ exactly occupies $z .^{32}$

\footnotetext{
${ }^{30}$ Likewise for the view that parthood $\mathrm{m}_{\mathrm{m}}$ can hold relative to temporally extended intervals composed of simple, sui generis instants. Since the property being a temporally extended interval composed of simple sui generis instants is plausibly intrinsic, the view in question will not be vulnerable to contraction arguments.

${ }^{31}$ A second objection to the Time-Slice Principle arises from the possibility of spacetimes that do not contain global time-slices. (Such spacetimes are permitted by General Relativity. For discussion, see Earman (1995).) On the assumption that parthood $_{m}$ can be instantiated within these spacetimes, the TimeSlice Principle must be rejected.

${ }^{32}$ We might add " . . . and y exactly occupies some superregion of z." I suspect that anyone who finds the Part Location Principle plausible will find the stronger principle roughly equally plausible.
} 
Likewise, the Rc view corresponds to

The Whole Location Principle:

Necessarily, for any material objects $x$ and $y$ and any $\mathrm{z}$, if $\mathrm{x}$ is a part $\mathrm{m}$ of $\mathrm{y}$ at $\mathrm{z}$, then $\mathrm{z}$ is a spacetime region and y exactly occupies $z .^{33}$

I assume that neither the Ra view nor the Rc view is plausible unless accompanied by the appropriate general principle. That is, I treat each view as a component of a larger, more general package.

Both packages fare quite well with respect to the considerations that we have discussed so far. We can begin with the single case intuition. There is nothing wildly implausible about the view that $\mathrm{Ra}$ is the only region at which $\mathrm{a}$ is a $\operatorname{part}_{\mathrm{m}}$ of $\mathrm{c}$, nor about the view that $\mathrm{Rc}$ is the only such region. Thus neither of those regions is obviously non-special in the way that Rblob is. If, for example, we endorsed the Rc view, we could not be accused of thereby making parthood $\mathrm{m}_{\mathrm{m}}$ seem excessively haphazard. (Though perhaps there is still something a bit arbitrary about preferring either the Part Location or the Whole Location Principle to the other.)

As for the intrinsicness intuition, neither of the relevant packages is vulnerable to a contraction argument. The problem with the Time-Slice Principle is that it sometimes treats plurally duplicate trios differently, forbidding one from instantiating parthood ${ }_{\mathrm{m}}$ but not forbidding the other. The Spacetime Principle also does this. This makes those principles (or the associated packages) vulnerable to contraction arguments. But neither the Whole Location Principle nor the Part Location Principle ever treats plurally duplicate trios differently, and so they are invulnerable to contraction arguments.

Consider the Whole Location Principle (WLP). To apply such a contraction argument to it, we would need to find 'plurally duplicate ordered triples', $\langle\mathrm{p}, \mathrm{o}, \mathrm{r}\rangle$ and $\left\langle\mathrm{p}^{*}, \mathrm{o}^{*}, \mathrm{r}^{*}\right\rangle$, such that the former but not the latter satisfies WLP's necessary condition on parthoodm. These triples would need to be such that (i) p, o, $\mathrm{p}^{*}$, and $\mathrm{o}^{*}$ are all material objects, (ii) $\mathrm{r}$ is a spacetime region that o exactly occupies, but (iii) either $\mathrm{r}^{*}$ is not a spacetime region or $\mathrm{o}^{*}$ does not exactly occupy $r^{*}$. Since being a spacetime region is plausibly an intrinsic property, and since exact occupation is plausibly an intrinsic relation, it seems that we will not be able to find plurally duplicate ordered triples that differ in this way. Parallel remarks apply, mutatis mutandis, to the Part Location Principle. This shows that both principles respect the intrinsicness intuition.

Despite these virtues, both principles have defects. Again we can start with the Rc view and the Whole Location Principle. The main problem for this package arises from questions about how to combine it with the widely accepted view that parthood $\mathrm{d}_{\mathrm{m}}$ is governed by a transitivity principle, or at least by some straightforward analogue of such a principle.

Strictly speaking, of course, transitivity can be a property of two-place relations only. Thus if we insist that parthood $\mathrm{d}_{\mathrm{m}}$ must turn out to be transitive in the strictest possible sense, we should cling to Absolutism; only Absolutists can take parthood ${ }_{m}$ (expressed by ' $<$ ') to be governed by

$$
\text { Transitivity2P } \quad \forall x \forall y \forall z[(x<y \& y<z) \rightarrow x<z]
$$

However it is often noted that there is a very natural and straightforward analogue of the transitivity principle that presumably governs parthood $_{m}$ if that relation has three argument places. If we symbolize the predicate ' $x$ is a part ${ }_{m}$ of $y$ at $z$ ' as ' $x<_{z} y$ ', then the analogue is:

$$
\text { Transitivity3P } \quad \forall x \forall y \forall z \forall w\left[\left(x<<_{w} y \& y<{ }_{w} z\right) \rightarrow x<{ }_{w} z\right]
$$

\footnotetext{
${ }^{33}$ We might add ". . . and x exactly occupies some subregion of z."
} 
In words, this says that if $\mathrm{x}$ is $\operatorname{part}_{\mathrm{m}}$ of $\mathrm{y}$ at $\mathrm{w}$ and $\mathrm{y}$ is $\operatorname{part}_{\mathrm{m}}$ of $\mathrm{z}$ at $\mathrm{w}$ then $\mathrm{x}$ is $\operatorname{part}_{\mathrm{m}}$ of $\mathrm{z}$ at $\mathrm{w}$. A somewhat different way of capturing the intuitive idea underlying this principle is to say that the three-place relation partm-of-at is such that for any $\mathrm{r}$, the $t w o$-place, 'indexed' relation part ${ }_{\mathrm{m}}$-ofat-r is transitive in the strict sense.

There are, of course, many other vaguely 'transitivity-like' principles that can be framed in terms of a three-place parthood predicate. For example, there is the principle that if $x$ is a part of $\mathrm{y}$ at some region and $\mathrm{y}$ is a part of $\mathrm{z}$ at some (perhaps different) region, then $\mathrm{x}$ is a part of $\mathrm{z}$ at some region. But I take it that, of these principles, Transitivity3P is by far the most natural analogue of Transitivity $2 \mathrm{P}$.

Return now to the Rc view and the Whole Location Principle. The problem for this package is not that it forces us to reject Transitivity3P; it doesn't. The problem is that the given package makes the principle impotent or inapplicable in certain contexts in which, intuitively, we should be able to use the principle to prove a certain fairly salient conclusion.

To see this, let us further specify Case 1, involving a, b, and c. Suppose that there is an additional singly located object, $b^{*}$, and at least one additional composite material object, $d$, which is also singly located, and which we can think of as being composed of $c$ and $b^{*}$. Let spacetime region $R b^{*}$ be the location of $\mathrm{b}^{*}$, and let spacetime region $R d$ be d's location. We can suppose that $\mathrm{Rb}^{*}$ does not overlap $\mathrm{Rc}$ and that $\mathrm{Rd}$ is the sum or union of these two regions. Finally, we can suppose that $\mathrm{Rd}$ is a proper subregion of Rslice and hence is temporally unextended. Thus the case can be represented by Fig. 3:

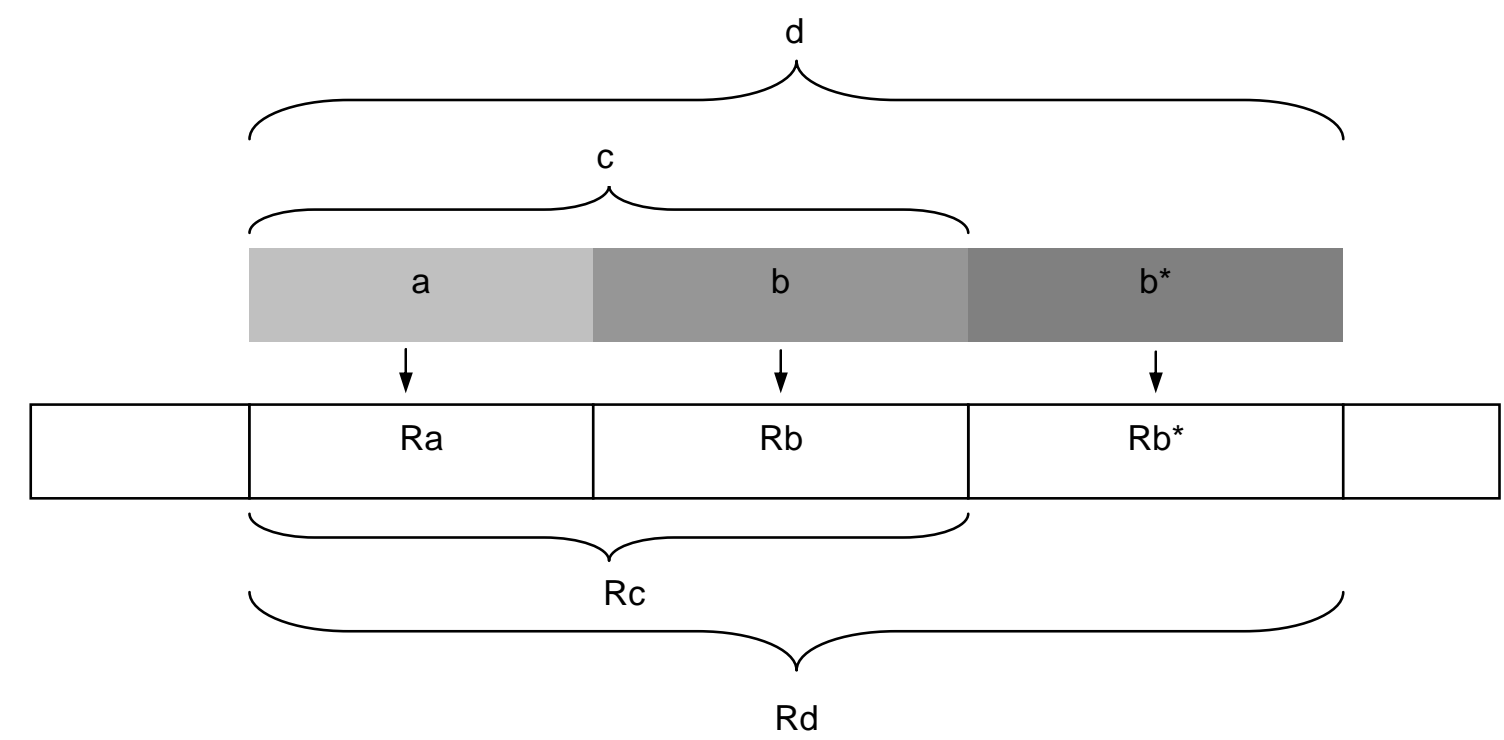

Figure 3

Intuitively, this is a case in which the transitivity of parthood $_{\mathrm{m}}$ (or the most natural appropriate analogue of it) should be applicable. We should be able to combine that principle with a premise to the effect that $a$ is a part $m$ of $c$ (at a certain region or regions, perhaps) and a premise to the effect that $c$ is a part $\mathrm{m}_{\mathrm{m}}$ of $d$ (at a certain region or regions, perhaps) to yield a conclusion to the effect that $a$ is a part $t_{m}$ of $d$ (at a certain region or regions perhaps). Somewhat more precisely, we should be able to formulate a three-premise argument that is formally valid in standard predicate logic and that has the following features. 
(i) Its first premise is a true atomic sentence to the effect that a is a $\operatorname{part}_{\mathrm{m}}$ of c, at whatever region or regions (if any) participate in the relevant 'instance' of parthood ${ }_{m}$. Thus, if parthood $_{\mathrm{m}}$ is a two-place relation, then the first premise of the argument contains a two-place predicate (expressing parthood $_{m}$ ) attached to names for a and c: for example, " $\mathrm{a}<\mathrm{c}$ " or "Pac". And if parthood $\mathrm{m}_{\mathrm{m}}$ is a three-place relation, then the first premise contains a three-place predicate (expressing parthood $\mathrm{d}_{\mathrm{m}}$ ) attached to names for $\mathrm{a}, \mathrm{c}$, and whatever region it is at which $\mathrm{a}$ is a part $\mathrm{m}_{\mathrm{m}}$ of $\mathrm{c}$ : for example, " $\mathrm{a}<_{\mathrm{r}} \mathrm{C}$ " or "Pacr". Mutatis mutandis if parthood $\mathrm{m}_{\mathrm{m}}$ has four or more argument places.

(ii) Its second premise is a true atomic sentence to the effect that $\mathrm{c}$ is a $\operatorname{part}_{\mathrm{m}} \mathrm{of} \mathrm{d}$, at whatever region or regions (if any) participate in the relevant instance of parthood ${ }_{m}$. Thus, if parthood $\mathrm{m}_{\mathrm{m}}$ is two-place, then the second premise of the argument might be the sentence "c $<\mathrm{d}$ ". Etc.

(iii) Its third premise is a true sentence that expresses the transitivity of parthood $\mathrm{m}_{\mathrm{m}}$ or (if parthood $_{\mathrm{m}}$ is not two-place) the most straightforward and natural analogue of that principle that can be framed in terms of a predicate whose adicity matches that of parthood $_{\mathrm{m}}$. Thus, if parthood $\mathrm{m}_{\mathrm{m}}$ is two-place, then the third premise might be the sentence " $\forall x \forall y \forall z[(x<y \& y<z) \rightarrow x<z]$," and if parthood ${ }_{m}$ is three-place, then the third premise might be " $\forall \mathbf{x} \forall \mathbf{y} \forall \mathbf{z} \forall \mathrm{w}\left[\left(\mathrm{x}<_{\mathrm{w}} \mathrm{y} \& \mathrm{y}<_{\mathrm{w}} \mathrm{z}\right) \rightarrow \mathrm{x}<_{\mathrm{w}} \mathrm{z}\right]$." Mutatis mutandis if parthood $_{\mathrm{m}}$ has four or more argument places.

(iv) Its conclusion is an atomic sentence to the effect that a is a part $\mathrm{m}_{\mathrm{m}}$ of $\mathrm{d}$, at whatever region or regions (if any) participate in the relevant instance of parthood $\mathrm{m}_{\mathrm{m}}$. Thus if parthood $_{m}$ is two-place, then the conclusion of the argument might be the sentence " $a<d$ ", and if parthood $d_{m}$ is three-place, the conclusion might be the sentence " $a<_{r}+d "$, where " $r$ " is a name for the region (whatever it is) at which a is a part ${ }_{\mathrm{m}}$ of $\mathrm{d}$. Mutatis mutandis if parthood $_{\mathrm{m}}$ has four or more argument places.

In sum, the relevant 'transitivity' principle should have a certain amount of power in this case; it should apply to the objects described above in such a way as to permit a sound argument of the given type. I take this to be a piece of intuitive data that our theories about parthood $\mathrm{m}_{\mathrm{m}}$ ought to accommodate. Call arguments of the given type transitivity arguments, and call the view that there is such an argument the transitivity intuition.

The transitivity intuition is easily accommodated by Absolutism. According to Absolutism, we can formulate a transitivity argument as follows:

Argument 1

Premise $1.1 \quad \mathrm{a}<\mathrm{C}$

Premise $1.2 \quad \mathrm{c}<\mathrm{d}$

Premise $1.3 \quad \forall x \forall y \forall z[(x<y \& y<z) \rightarrow x<z]$

Conclusion $1 \quad a<d$

The transitivity intuition can also be accommodated by 3P, provided that we do not combine this view with the wrong answer to the Restriction Question. Suppose, for example, that both 3P and the Spacetime Principle are true. Then the following counts as a transitivity argument:

Argument 2

Premise 2.1

Premise $2.2 \quad c<_{R \max } \mathrm{d}$

Premise $2.3 \quad \forall x \forall y \forall z \forall w\left[\left(x<_{w} y \& y<<_{w} z\right) \rightarrow x<<_{w} z\right]$

Conclusion $2 \quad a<_{\text {Rmax }} d$ 
Similarly, if 3P and the Time-Slice Principle were true, we could formulate a transitivity argument just by replacing each occurrence of "Rmax" above with an occurrence of "Rslice". So, despite their other faults, the Spacetime Principle and the Time-Slice Principle both fare well with respect to the transitivity intuition.

Not so for either the Whole Location Principle or the Part Location Principle. Given 3P and the Whole Location Principle, together with the demand to formulate premises and a conclusion that fit the specifications set out in (i) - (iv), the best we can do is:

Argument 3

Premise 3.1

Premise 3.2

Premise 3.3 $\forall \mathrm{x} \forall \mathrm{y} \forall \mathrm{z} \forall \mathrm{w}[(\mathrm{x}<\mathrm{w} \mathrm{y} \& \mathrm{y}<\mathrm{w} z) \rightarrow \mathrm{x}<\mathrm{w} z]$

Conclusion $3 \quad \mathrm{a}<\mathrm{Rd} d$

The obvious problem with Argument 3 is that it is not formally valid: the subscript in Premise 3.1 does not match the subscript in Premise 3.2, which it would need to in order for Premise 3.3

(a.k.a. Transitivity3P) to get any traction. But of course we cannot change the argument to fix this without defying the Whole Location Principle. Given the set-up of our case, that principle tells us that the only region at which a is a part $\mathrm{m}_{\mathrm{m}}$ of $\mathrm{c}$ is $\mathrm{Rc}$ and that the only region at which $\mathrm{c}$ is a part $\mathrm{m}_{\mathrm{m}}$ of $\mathrm{d}$ is a different region, $\mathrm{Rd}$. In other words, the Whole Location Principle (unlike the Spacetime Principle or the Time-Slice Principle) tells us that there is no common region at which both a is a part $_{\mathrm{m}}$ of $\mathrm{C}$ and $\mathrm{C}$ is a part $\mathrm{m}_{\mathrm{m}}$ of $\mathrm{d}$. But without such a common region, we cannot use Transitivity3P to derive a conclusion about a's being a part $\mathrm{m}_{\mathrm{m}}$ of $\mathrm{d}$.

One might object that our 'transitivity' principle is too weak, and in particular that we should replace it with

$$
\text { Transitivity3P+ } \quad \forall \mathbf{x} \forall \mathbf{y} \forall \mathbf{z} \forall \mathbf{w} \forall \mathrm{w}^{*}\left[\left(\mathrm{x}<_{\mathrm{w}} \mathrm{y} \& \mathrm{y}<_{\mathrm{w}^{*}} \mathbf{z}\right) \rightarrow \mathrm{x}<_{\mathrm{w}^{*} \mathrm{z}}\right]
$$

This would make Argument 3 formally valid, but Transitivity3P+ is much too strong to be plausible to any multi-locationist who takes material objects to vary mereologically from one location to another. (Hence feature (iii), which requires that the principle in question be true, is not plausibly satisfied.) Presumably any such philosopher will want to allow for the following type of case:

Case 2. Bob is multi-located; he exactly occupies the spacetime regions R1 and R2. As he is at R1, he has both a left hand (Hand) and a left thumb (Thumb) as parts. Hand exactly occupies a proper subregion of R1, namely R1Hand, and Thumb exactly occupies a proper subregion of R1Hand, namely R1Thumb. However, as Bob is at R2, he has Hand as a part (it exactly occupies R2Hand, a proper subregion of R2) but he does not have Thumb as a part. Thumb does not exactly occupy any subregion of R2.

As applied to Case 2, 3P and the Whole Location Principle tell us that Thumb is a part $_{\mathrm{m}}$ of Hand at R1Hand and that Hand is a part $\mathrm{m}_{\mathrm{m}}$ of Bob at R1 and at R2. Together with Transitivity3P+, this entails that Thumb is a part $\mathrm{m}_{\mathrm{m}}$ of Bob at R2. But this is clearly wrong: Thumb is not a part $\mathrm{m}_{\mathrm{m}}$ of Bob at $\mathrm{R} 2$. Transitivity $3 \mathrm{P}+$ is a non-starter. ${ }^{34}$

\footnotetext{
${ }^{34}$ One might be tempted to replace Transitivity3P+ with:

Transitivity3P $\exists \quad \forall \mathbf{x} \forall \mathbf{y} \forall \mathbf{z} \forall \mathbf{w} \forall \mathbf{w}^{*}\left[\left(\mathbf{x}<{ }_{\mathrm{w}} \mathbf{y} \& \mathbf{y}<\mathrm{w}^{*} \mathbf{z}\right) \rightarrow \exists \mathbf{w}^{* *}\left(\mathbf{x}<\mathbf{w}^{* *} \mathbf{z}\right)\right]$

But this is vulnerable to a similar counterexample. Mary donates a kidney (Kidney3) to John. There is a cell (Cell3) which, intuitively, is a part of Kidney3 only when that kidney is a part of Mary: the cell dies
} 
A more promising suggestion is to replace Transitivity3P with a principle somewhat weaker than Transitivity3P+. If we symbolize the predicate ' $\mathrm{x}$ is a subregion of $y$ ' as ' $\mathrm{x}$ 드' then we can state the new principle as:

Transitivity3Psub $\quad \forall \mathrm{x} \forall \mathrm{y} \forall \mathrm{z} \forall \mathrm{w} \forall \mathrm{w}^{*}\left[\left(\mathrm{x}<_{\mathrm{w}} \mathrm{y} \& \mathrm{y}<_{\mathrm{w} * \mathrm{Z}} \& \mathrm{w}\right.\right.$ 드 $\left.\left.* \mathrm{w}^{*}\right) \rightarrow \mathrm{x}<_{\mathrm{w}} * \mathrm{Z}\right]$

This principle does not yield the absurd conclusion that Thumb is a part $\mathrm{m}_{\mathrm{m}}$ of Bob at $\mathrm{R} 2$. To get that result from Transitivity3Psub, we would also need the claim that R1Hand (the region at which Thumb is a part $\mathrm{m}_{\mathrm{m}}$ of Hand) is a subregion of $\mathrm{R} 2$ (this being a region at which Hand is a part $_{m}$ of Bob). But given the set-up of Case 2, this claim is false: recall that Thumb exactly occupies a subregion of R1Hand but does not exactly occupy any subregion of R2. This entails that R1Hand is not a subregion of R2. So Case 2 poses no problem for Transitivity3Psub.

Another point in favor of Transitivity3Psub is that, as applied to Case 1 (involving a, b, $c$, and $d$ ), it can be used to show that a is a part ${ }_{m}$ of $d$ at $R d$. For consider:

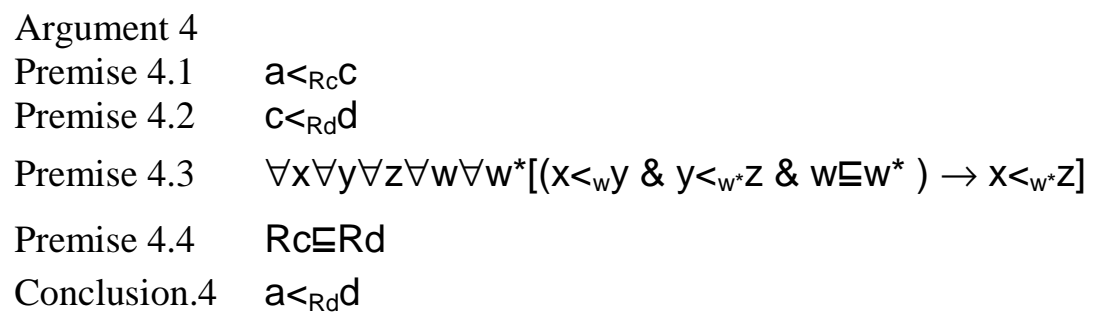

Argument 4 is formally valid and, given 3P and the Whole Location Principle, all of its premises are overwhelmingly plausible. It may seem, therefore, that Transitivity3Psub allows the defender of the Whole Location Principle to accommodate the transitivity intuition.

But this would be a mistake, for two reasons. First, recall the content of the transitivity intuition - viz., that there is some formally valid, three-premise argument with features (i) - (iv). Argument 4 is no such argument. It has four premises, and it obviously cannot be converted into a formally valid, three-premise argument without strengthening one of its first three premises, or weakening its conclusion, in a way that would make it forfeit one of features (i) - (iv).

Second, even as it stands, Argument 4 clearly does not possess feature (iii). I take it that no one would be tempted to suggest that Transitivity3Psub is the most natural and straightforward three-place counterpart of Transitivity2P. Far from it: Transitivity3Psub is cooked up and cobbled together in an attempt to reconcile opposing motivations - the (to my mind well-justified) desire to accommodate the transitivity intuition, and the (to my mind misguided) desire to preserve the Whole Location Principle. The most egregious symptom of this

and is shed well before the kidney is donated to John. In that case we might have the following: Kidney3 exactly occupies many regions, among them Rmk, which does not overlap any region that John exactly occupies, and Rjk, which is a proper subregion of a region $(\mathrm{Rj})$ that John exactly occupies. Cell3 exactly occupies many regions, among them Rcell, which is a proper subregion of Rmk, but Cell3 does not exactly occupy any region that overlaps a region that John exactly occupies. Then, given the Whole Location Principle, it is plausible that: (i) Cell3 is a part $\mathrm{m}_{\mathrm{m}}$ of Kidney3 at Rmk and (ii) Kidney3 is a part $\mathrm{m}_{\mathrm{m}}$ of John at $\mathrm{Rj}$, and yet, contrary to Transitivity $3 \mathrm{P} \exists$, there is nothing at which Cell3 is a part $\mathrm{m}_{\mathrm{m}}$ of John.

A second (and perhaps more obvious) problem for this suggestion is that, even if the principle were plausible (which it is not), it's not strong enough to combine with the sorts of premises I've described to yield, as a conclusion, an atomic sentence like " $\mathrm{a}<_{\mathrm{Rd}} \mathrm{d}$ ", which is what we need. All it would give us is: " $\exists x\left(a<_{x} d\right)$ ". Thanks to Adam Sennet for discussion. 
is the fact that the sentence expressing Transitivity3Psub contains an additional predicate, ' $x \sqsubseteq y$ ', over and above ' $x<_{z} y$ '. Even if the former ends up being definable in terms of the latter (a related question is addressed at the end of section 5), the fact that the extra material is needed points to the complexity and unnaturalness of the principle.

Admittedly, Argument 4 is much better than nothing. It is valid, it has plausible premises, and it resembles a transitivity argument; it comes much closer to satisfying the transitivity intuition than does, say, the invalid Argument 3. So some friends of $3 \mathrm{P}$ and the Whole Location Principle may be willing to bite this bullet and deny the letter of the transitivity intuition, given that they have Argument 4 to fall back on. The crucial point is merely that there is a bullet to bite here. After all, Absolutists have no trouble satisfying the letter of the transitivity intuition. Likewise for friends of 3P who endorse either the Spacetime Principle or the Time-Slice Principle. And likewise for friends of 4P, as I explain in section 4. So I think that I am well within

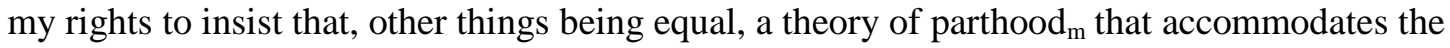
transitivity intuition is more plausible than one that does not.

This completes my discussion of the transitivity intuition and its bearing on the Whole Location Principle. I assume that the friend of that principle cannot do any better than Argument 4 with regard to satisfying the transitivity intuition, and that Argument 4 leaves much to be desired.

I will now turn briefly to the package consisting of the Ra view and the Part Location Principle. This package is vulnerable to a parallel argument. For if we accept this package, and if we strictly comply with the demand to formulate premises and a conclusion that fit the specifications set out in (i) - (iv), then our best attempt at a transitivity argument will be:

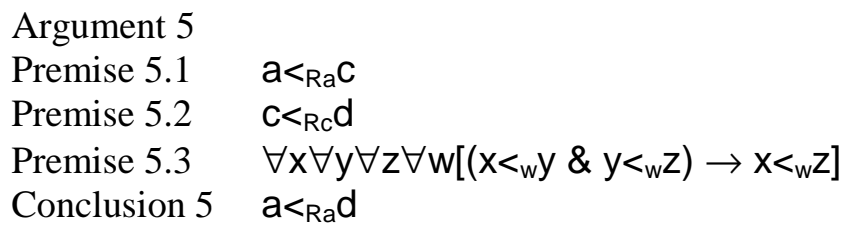

This argument, like Argument 3, is not formally valid: the subscripts in the first two premises don't match. Like the Whole Location Principle, the Part Location Principle tells us that there is no common region at which both $\mathrm{a}$ is a part $\mathrm{m}_{\mathrm{m}}$ of $\mathrm{c}$ and $\mathrm{c}$ is a $\operatorname{part}_{\mathrm{m}}$ of $\mathrm{d}$. We can, as before, formulate something that resembles a transitivity argument: we can replace Premise 5.3 with

Premise 5.3* $\quad \forall x \forall y \forall z \forall w \forall w^{*}\left[\left(x<w y \& y<w^{*} z \& w \subseteq w^{*}\right) \rightarrow x<<_{w} z\right]$

and add a premise to the effect that Ra is a subregion of Rc. But, like Argument 4, the result will still fall short of being a genuine transitivity argument. ${ }^{35}$ So the Part Location Principle fares no better than the Whole Location Principle. Both conflict with the transitivity intuition. This is their main defect. ${ }^{36}$

\footnotetext{
${ }^{35} \mathrm{We}$ might try strengthening the relevant transitivity principle in a way that is tailored, not to the Whole Location Principle (as was Transitivity3P+), but rather to the Part Location Principle - viz.:$$
\text { Transitivity3P+** } \quad \forall x \forall y \forall z \forall w \forall w^{*}\left[\left(x<w y \& y<w^{*} z\right) \rightarrow x<<_{w} z\right]
$$

But this principle is vulnerable to the same counterexample (Case 2) as was Transitivity3P+.

${ }^{36} \mathrm{~A}$ variant of this problem also applies to an appealing pluralist answer to our question about a and $\mathrm{C}$ (inspired by Hudson 2001: 61-71). Suppose that one thinks that $\mathrm{a}$ is a part $\mathrm{m}$ of $\mathrm{c}$ at every region that is both a superregion of a's location and a subregion of c's location. (This includes, among other regions, Ra, $\mathrm{Ra}+$, and Rc.) This view is most plausible in the context of the following general principle:
} 


\subsubsection{The Two Case Intuition}

There is also a second objection to these two principles that deserves a brief mention. In addition to conflicting with the transitivity intuition, they both conflict with what I will call the two case intuition. Consider the situations represented in Fig. $4 .{ }^{37}$

Tweenism

Necessarily, for any material objects $\mathrm{x}$ and $\mathrm{y}$ and any spacetime region $\mathrm{R}$, if $\mathrm{x}$ is a part of $y$ at $R$, then $R$ is a superregion of some location of $x$ and a subregion of some location of $\mathrm{y}$.

The Tweenist can plausibly regard the following as a transitivity argument: Premise $\mathrm{T} 1: \mathrm{a}<{ }_{\mathrm{RC}} \mathrm{C}$. Premise T2: $c<_{R_{C}} d$. Premise T3: $\forall x \forall y \forall z \forall w\left[\left(x<_{w} y \& y<{ }_{w} z\right) \rightarrow x<<_{w} z\right]$. Conclusion: $a<_{R c} d$. The Tweenist will see $\mathrm{T} 1$ as being true on the grounds that Rc is a (proper) superregion of a's location and an (improper) subregion of c's location, and he will see T2 as being true on the grounds that Rc is an (improper) superregion of c's location and a (proper) subregion of d's location. Finally, he will see the conclusion as being true on the grounds that Rc is a (proper) superregion of a's location and a (proper) subregion of d's location. So it appears that Tweenism can accommodate the transitivity intuition as stated.

Suppose, however, that we introduce a further object, $\mathrm{e}^{\star}$, that we can think of as being composed of $d$ together with another small object $b^{\star *}$, where $b^{\star *}$ s lone location, $R b^{\star *}$, is disjoint from $R d$, and where $e^{\star}$ 's lone location, $R e^{*}$, is the sum or union of $R^{* *}$ and $R d$. Then it seems that we ought to be able to construct an argument whose conclusion is an atomic sentence to the effect that a is a part of $^{*}$ (at certain region(s), perhaps), and that we ought to be able to construct this argument merely by adding just one additional premise to those from our earlier transitivity argument - viz., an atomic sentence to the effect that $d$ is a part $t_{m}$ of $e^{*}$ (at certain region(s), perhaps). The Tweenist cannot satisfy this demand. According to him, the only regions at which $d$ is a part $t_{m}$ of $e^{*}$ are superregions of $\mathrm{Rd}$, and none of these is a region at which $\mathrm{a}$ is a part $\mathrm{m}_{\mathrm{m}}$ of $\mathrm{c}$ (all of which are subregions of Rc). I.e., on his view, there is no single region at which (i) a is a part $\mathrm{m}_{\mathrm{m}}$ of $\mathrm{c}$, (ii) $\mathrm{c}$ is a part $\mathrm{m}_{\mathrm{m}}$ of $\mathrm{d}$, and (iii) $d$ is a part $\mathrm{m}_{\mathrm{m}}$ of $\mathrm{e}^{*}$, although there are regions at which the first two clauses hold and other regions at which the second two clauses hold. As I indicate in note 41 , this case poses no problem for $4 \mathrm{P}$.

${ }^{37}$ According to most multi-locationists (endurantists and MROists), these situations will be at best extremely remote possibilities, and so the failure to accommodate them will hardly seem to be much of a vice. The one multi-locationist who would seem to be committed to their possibility is Hudson (2001). On his view, as I noted earlier, ordinary objects are temporally extended 'worms' that typically have many (mostly overlapping) 4D locations. The idea, roughly, is to say that each of the many precisely demarcated regions that we would normally regard as a candidate for being my (e.g.) location actually is one of my locations. To allow for Case 3 below, in which the larger object Fred is mono-located (while Fredpart is multi-located), we would need to suppose that for some reason, the usual sources of boundary vagueness are absent for Fred but are present for Fredpart. (Perhaps Fred's surface is especially tightly integrated and sharply demarcated from its surroundings.) Case 4 is easier. Just let the smaller object Gretapart be a monolocated simple, and let Greta be multi-located in the way Hudson regards as typical. 

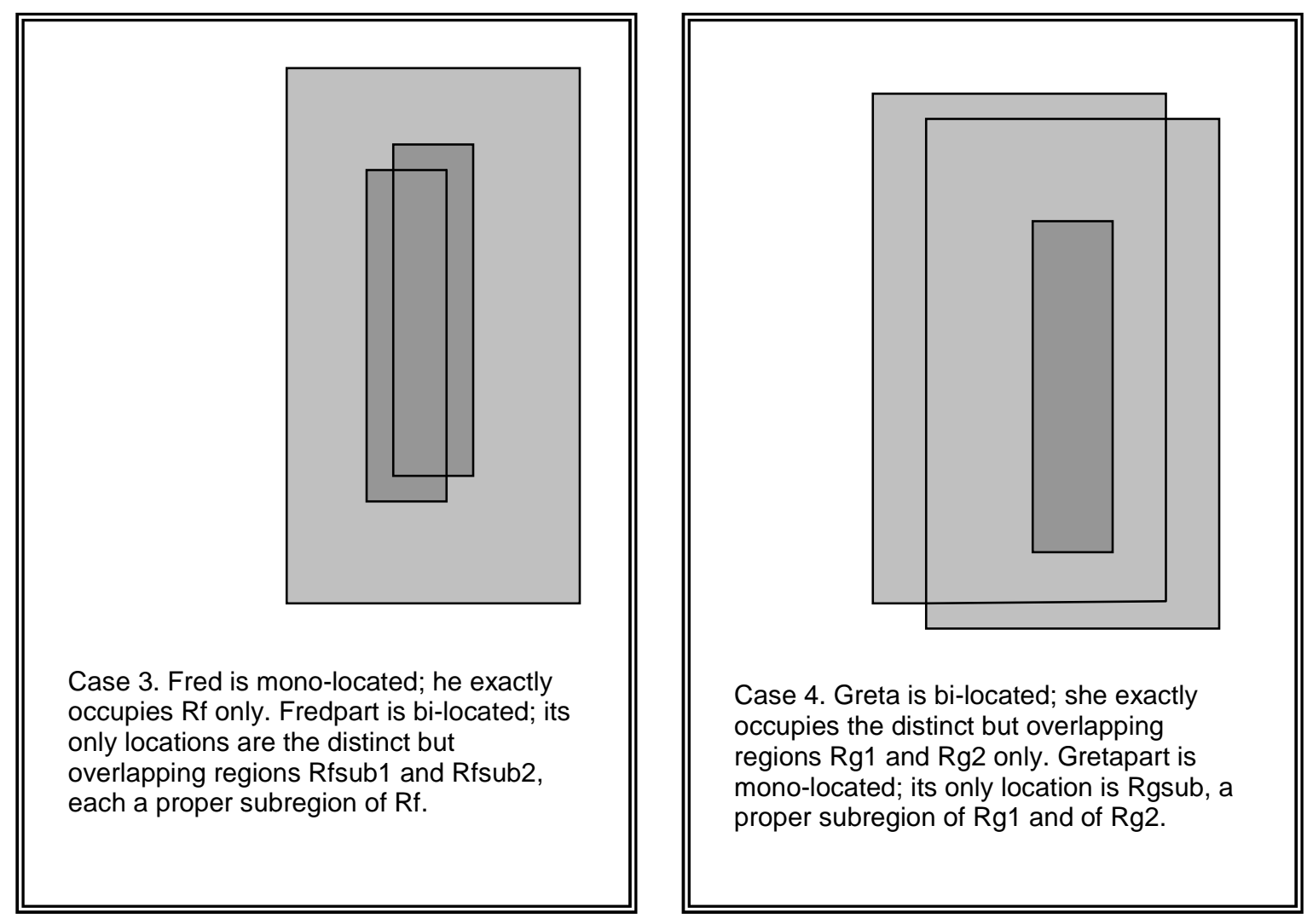

Figure 4

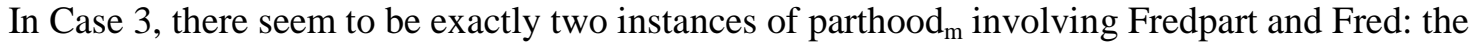
former object seems to be part $_{\mathrm{m}}$ of the later object twice over. The Part Location Principle allows for this. Since Fredpart has two different locations, the Part Location Principle lets us say that Fredpart is part $_{\mathrm{m}}$ of Fred both at Rfsub1 and at Rfsub1. In other words, it lets us say that two different ordered triples involving Fredpart and Fred ( $\langle$ Fredpart, Fred, Rfsub1 $\rangle$ and $\langle$ Fredpart,

Fred, Rfsub2 $\rangle$ ) are such their members instantiate parthoodm in the order specified by the triple. The Whole Location Principle, however, has trouble with Case 3. Since Fred has only one location, this principle tells us that there is at most one region at which Fredpart is a part $\mathrm{m}_{\mathrm{m}}$ of Fred, hence that there is at most one instance of $\operatorname{parthood}_{\mathrm{m}}$ associated with the given pair of objects.

Case 4 elicits similar intuitive judgments: there seem to be two instances of parthood ${ }_{m}$ involving Gretapart and Greta. But in this case, it is the Whole Location Principle that allows for the intuitively correct verdict and the Part Location Principle that fails. Since Greta exactly occupies both Rg1 and Rg2, the Whole Location Principle lets us say: Gretapart is a part $\mathrm{m}_{\mathrm{m}}$ of Greta both at Rg1 and at Rg2. On the other hand, since Gretapart has only one location, the Part Location Principle forces us to say that there is at most one region at which Gretapart is a part $_{\mathrm{m}}$ of

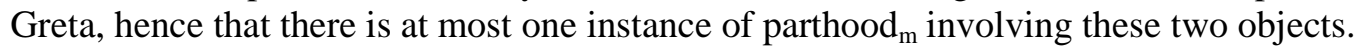

The two case intuition, then, is the following conjunction: there are two instances of parthood $_{m}$ involving Fredpart and Fred, and there are two instances of parthood ${ }_{m}$ involving Gretapart and Greta. Neither the Part Location Principle nor the Whole Location Principle can handle both conjuncts of the intuition, although each principle handles one conjunct. 
Unlike the previous intuitions that I have discussed, the two case intuition poses problems for virtually all of the views about parthood $\mathrm{d}_{\mathrm{m}}$ considered so far. According to Absoluteness, there is only one ordered n-tuple involving Fredpart and Fred whose members instantiate parthood $\mathrm{m}_{\mathrm{m}}$ in the order specified - namely, the ordered pair 〈Fredpart, Fred $\rangle$. Thus it tells us that there is only one instance of parthood ${ }_{\mathrm{m}}$ involving these objects. Mutatis mutandis for Gretapart and Greta. Absoluteness fails for both cases. (Of course, it is highly unlikely that any Absolutist would accept the possibility of Cases 3 or 4, so we should be hesitant to think of these cases as the basis of a non-question-begging argument against Absolutism.)

Our 3P-ist views divided into two categories: pluralist and non-pluralist. As for the pluralist answers to our original question about a and c, it seems that on any remotely plausible way of generalizing these answers, we would get the result that Fredpart is a part $\mathrm{m}_{\mathrm{m}}$ of Fred more than twice (and likewise for Gretapart and Greta). But having too many of the relevant instances is no better than having too few.

What about the Spacetime Principle? On the assumption that the regions involved in Cases 3 and 4 all belong to a single spacetime, this principle gives us the result that Fredpart is a part $_{\mathrm{m}}$ of Fred at most once, and likewise for Gretapart and Greta. Similarly, on the assumption that these regions are all subregions of exactly one common global time-slice, the Time-Slice Principle delivers this same result. So the problems posed by the two case intuition are not specific to the Whole Location Principle or the Part Location Principle. And yet we will see that these problems can be avoided if we reject $3 \mathrm{P}$ in favor of $4 \mathrm{P}$.

\section{Four-Place Parthood}

According to $4 \mathrm{P}$, parthood $\mathrm{d}_{\mathrm{m}}$ is a four-place relation that can be expressed by the predicate ' $\mathrm{x}$ at $\mathrm{W}$ is a part $\mathrm{m}_{\mathrm{m}}$ of $\mathrm{y}$ at $\mathrm{z}$ '. Given multi-location and $4 \mathrm{P}$, one natural response to the Restriction Question $^{38}$ is to suggest that parthood $_{\mathrm{m}}$ is governed by

LLP: $\quad$ Necessarily, for any material objects $x$ and $y$ and any spacetime regions $\mathrm{w}$ and $\mathrm{z}$, if $\mathrm{x}$ at $\mathrm{w}$ is a part $\mathrm{m}$ of $\mathrm{y}$ at $\mathrm{z}$, then $\mathrm{x}$ exactly occupies $w$ and y exactly occupies $z .^{39}$

I will now argue that LLP avoids all of the problems discussed in section 3. In particular, it respects (i) the single case intuition, (ii) the intrinsicness intuition, (iii) the transitivity intuition, and (iv) the two case intuition.

We can start with (i). As applied to Case 1, LLP tells us that there is just one ordered ntuple whose members instantiate $\operatorname{parthood}_{\mathrm{m}}$ (in the order given by the n-tuple) - namely, the ordered quadruple $\langle\mathrm{a}, \mathrm{Ra}, \mathrm{c}, \mathrm{Rc}\rangle$. After all, a exactly occupies only Ra, and c exactly occupies only Rc. So, with just one such n-tuple, we get the result that there is just one instance of parthood $_{\mathrm{m}}$ involving $\mathrm{a}$ and c; in slightly different terms, $\mathrm{a}$ is a $\operatorname{part}_{\mathrm{m}}$ of $\mathrm{c}$ just once. Moreover, the suggestion that $\langle\mathrm{a}, \mathrm{Ra}, \mathrm{c}, \mathrm{Rc}\rangle$ is the one and only n-tuple with the relevant feature cannot be accused of being arbitrary or of making parthood ${ }_{m}$ seem haphazard. $R a$ and $R c$ are quite special as far as a and $\mathrm{c}$ are concerned, for obvious reasons.

Next consider (ii), the intrinsicness intuition. Here again, LLP fares well. As I noted earlier, being a spacetime region is plausibly an intrinsic property and exact occupation is plausibly an intrinsic relation. So it would seem that if one ordered quadruple of entities is eligible for parthood $\mathrm{m}_{\mathrm{m}}$ according to LLP, then any plurally duplicate quadruple is also eligible. In

\footnotetext{
${ }^{38}$ Or a variant of that question framed in terms that are more appropriate to 4P.

${ }^{39}$ We might also add " . . . and $w$ is a subregion of z." I suspect that anyone who finds LLP plausible will find the strengthened version roughly equally plausible.
} 
other words, LLP never treats plurally duplicate ordered quadruples differently. So far as LLP is concerned, then, its proponents are free to hold that parthood $_{\mathrm{m}}$ is an intrinsic relation.

We can turn now to (iii), the transitivity intuition. It seems to me that given 4P and LLP, one principle stands out as the most straightforward and natural analogue of Transitivity2P. If we symbolize the predicate ' $x$ at $w$ is a part $_{m}$ of $y$ at $z$ ' as ' $x_{w}<z y$ ', then we can formulate that principle as

Transitivity4P: $\forall x \forall r 1 \forall y \forall r 2 \forall z \forall r 3\left[\left(x_{r 1}<_{r 2} y \& y_{r 2}<r_{r 3} z\right) \rightarrow x_{r 1}<r_{r 3} z\right]$

In words, this says that if $\mathrm{x}$ at $\mathrm{r} 1$ is a part $\mathrm{m}_{\mathrm{m}}$ of $\mathrm{y}$ at $\mathrm{r} 2$ and if $\mathrm{y}$ at $\mathrm{r} 2$ is a $\operatorname{part}_{\mathrm{m}}$ of $\mathrm{z}$ at $\mathrm{r} 3$, then $\mathrm{x}$ at $\mathrm{r} 1$ is a part ${ }_{\mathrm{m}}$ of $\mathrm{z}$ at $\mathrm{r} 3{ }^{40}$ To make the analogy easier to grasp, it may be helpful to define a two-place relation of pair-parthood:

$$
\text { D5 } p \text { is a pair-part of } p^{*}=d f . \exists x \exists r 1 \exists y \exists r 2\left[p=\langle x, r 1\rangle \& p^{*}=\langle y, r 2\rangle \& x_{r 1}<{ }_{r 2} y\right] \text {. }
$$

Then, given the existence of the relevant pairs, Transitivity4P is equivalent to the claim that pairparthood is transitive in the strict sense.

Suppose, then, that Transitivity4P is a sufficiently natural analogue of Transitivity2P. In that case, the friend of $4 \mathrm{P}$ will say that a transitivity argument can be formulated as follows:

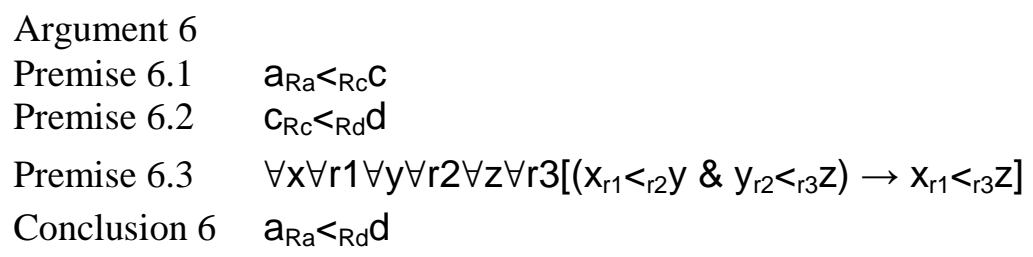

Premise 6.1 says that a at $R a$ is a part ${ }_{m}$ of $c$ at $R c$, and Premise 6.2 says that $c$ at $R c$ is a part of $\mathrm{d}$ at $\mathrm{Rd}$. Since $\mathrm{Ra}, \mathrm{Rc}$, and $\mathrm{Rd}$ are locations of $\mathrm{a}, \mathrm{c}$, and d, respectively, friends of LLP will find these premises highly plausible. Together with Premise 6.3, they yield a formally valid argument for Conclusion 6, which says that a at Ra is a part $\mathrm{m}_{\mathrm{m}}$ of $\mathrm{d}$ at Rd. This is exactly the sort of conclusion concerning $\mathrm{a}$ and $\mathrm{d}$ that we initially hoped to be able to prove. It should be clear, therefore, that if we adopt $4 \mathrm{P}$ and LLP, we can easily accommodate the transitivity intuition. ${ }^{41}$

Finally, consider (iv), the two case intuition. It says that there are exactly two instances of parthood $_{\mathrm{m}}$ involving Fredpart and Fred (in Case 3) and exactly two instances of parthood $\mathrm{m}_{\mathrm{m}}$ involving Gretapart and Greta (in Case 4). Unlike any of the other views that we have considered so far, the 4P+LLP package allows for this without any strain at all.

\footnotetext{
${ }^{40}$ Obviously, there are many vaguely transitivity-like principles that can be framed in terms of our fourplace parthood predicate. I suspect that the most serious rival to Transitivity4P is

Transitivity4P* $\quad \forall x \forall y \forall z \forall r\left[\left(x_{r}<r y \& y_{r}<r z\right) \rightarrow x_{r}<r z\right]$

Transitivity4P* says that if $\mathrm{x}$ at $\mathrm{r}$ is a part $\mathrm{P}_{\mathrm{m}}$ of $\mathrm{y}$ at $\mathrm{r}$, and $\mathrm{y}$ at $\mathrm{r}$ is a $\operatorname{part}_{\mathrm{m}}$ of $\mathrm{z}$ at $\mathrm{r}$, then $\mathrm{x}$ at $\mathrm{r}$ is a $\operatorname{part}_{\mathrm{m}}$ of $\mathrm{z}$ at $r$. This is quite weak. If $x$ and $y$ are material objects and $r$ is a spacetime region, then, given LLP, $x$ at $r$ is a part $_{\mathrm{m}}$ of $\mathrm{y}$ at $\mathrm{r}$ only if $\mathrm{x}$ and $\mathrm{y}$ both exactly occupy $\mathrm{r}$. So a trio of material objects can satisfy the antecedent of Transitivity $4 \mathrm{P}^{*}$ only if they all share a common location - i.e., only if they all exactly occupy the very same region. It would come as a big surprise, I think, if this were the strongest transitivity-like principle that parthood $\mathrm{m}_{\mathrm{m}}$ obeys. Typically we think that this relation is governed by a transitivity-like principle that applies to trios of non-co-located objects.

${ }^{41}$ Likewise, the augmented case described in note 36 poses no problem. We simply add the following premise: $d_{R d}<R^{*} e^{*}$. The result is a formally valid four-premise argument for the conclusion, " $a_{R a}<R_{e^{*}} e^{*}$, as desired.
} 
In Case 3, Fredpart has exactly two locations, Rfsub1 and Rfsub2, and Fred has exactly one location, Rf. Together with LLP, this allows us to say that

- Fredpart at Rfsub1 is a part $\mathrm{m}_{\mathrm{m}}$ of Fred at Rf, and

- Fredpart at Rfsub2 is a part $t_{m}$ of Fred at Rf;

and it entails that (i) for no $\mathrm{x}$ aside from Rfsub1 or Rfsub2 is there a y such that Fredpart at $\mathrm{x}$ is a part $_{\mathrm{m}}$ of Fred at $\mathrm{y}$ and (ii) for no $\mathrm{y}$ aside from Rf is there an $\mathrm{x}$ such that Fredpart at $\mathrm{x}$ is a part $_{\mathrm{m}}$ of Fred at y. In other words, there are no ordered n-tuples involving Fredpart and Fred aside from $\langle$ Fredpart, Rfsub1, Fred, Rf $\rangle$ and 〈Fredpart, Rfsub2, Fred, Rf $\rangle$ whose members instantiate parthood $_{\mathrm{m}}$ in the order given by the n-tuple. ${ }^{42}$ On the assumption that there are exactly two such

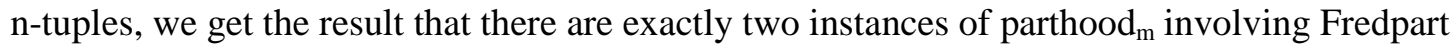
and Fred - i.e., that Fredpart is a part $t_{m}$ of Fred exactly twice. And of course this is what we wanted.

Parallel remarks apply to Case 4, in which Gretapart has exactly one location, Rgsub, and Greta has exactly two locations, $\operatorname{Rg} 1$ and $\mathrm{Rg} 2$. Together with LLP, this lets us say that

- Gretapart at Rgsub is a part $\mathrm{m}_{\mathrm{m}}$ of Greta at $\mathrm{Rg} 1$, and

- Gretapart at Rgsub is a part ${ }_{\mathrm{m}}$ of Greta at $\mathrm{Rg} 2$; and it entails that there are no ordered n-tuples involving Gretapart and Greta aside from 〈Gretapart, Rgsub, Greta, Rg1〉 and 〈Gretapart, Rgsub, Greta, Rg2〉 whose members instantiate parthood $_{m}$ in the order given by the $n$-tuple. ${ }^{43}$ Thus we are free to say that there are exactly two instances of parthood ${ }_{m}$ involving Gretapart and Greta - i.e., that Gretapart is a part $\mathrm{m}_{\mathrm{m}}$ of Greta exactly twice. 4P+LLP has no trouble handling the two case intuition.

Let me summarize my results so far. Given $3 \mathrm{P}$, every remotely plausible answer to the Restriction Question violates both the two case intuition and (more importantly) either the single case intuition, the intrinsicness intuition, or the transitivity intuition. Given 4P, however, there is at least one quite natural answer to the Restriction Question that respects all four of those intuitions. This gives the multi-locationist a very powerful reason to prefer 4P to 3P.

Are there any reasons to have the opposing preference? In my view, the most serious objection to $4 \mathrm{P}$ is this. Other things being equal, the more closely a theory of parthood $\mathrm{m}_{\mathrm{m}}$ resembles Absolutism, the better. (This principle was invoked in support of the single case intuition and the intrinsicness intuition.) The most obvious respect in which a theory of parthood $\mathrm{m}_{\mathrm{m}}$ can resemble Absolutism is with regard to the adicity that the theory attributes to parthood $\mathrm{m}_{\mathrm{m}}$. But in that respect, $3 \mathrm{P}$ clearly resembles Absolutism more closely than does 4P: after all, 3 is closer to 2 than 4 is!

I concede that, ceteris paribus, we should try to minimize the number of extra argument places that we posit in parthood $_{\mathrm{m}}$ (beyond the ordinary two). But, first, it seems to me that this consideration is rather weak and easily overridden by the other factors that I have discussed.

Second, 4P may resemble Absolutism more closely than does 3P even with regard to considerations about argument places themselves. After all, Absolutism tells us that the argument places in parthood $_{\mathrm{m}}$ are evenly divided between (i) those that are especially closely associated with 'the part' and (ii) those that are especially closely associated with 'the whole.' 4P, when combined with LLP, tells us exactly the same thing. For according to 4P+LLP, parthood $\mathrm{m}_{\mathrm{m}}$ has four argument places, two of which are reserved for the part or one of its locations, and the other two of which are reserved for the whole or one of its locations. Obviously 3P cannot match this.

\footnotetext{
${ }^{42}$ More carefully: given 4P and LLP, there are no such ordered n-tuples in which Fredpart is the first element and Fred is the third element aside from the given pair of ordered quadruples. LLP is silent, for example, as to whether $(*)$ Rfsub1 at Fredpart is a partm of Rf at Fred. But I take it that even if $(*)$ is true, we still have the result that Fredpart is a partm of Fred exactly twice.

${ }^{43}$ More carefully: given 4P and LLP, there are no such ordered n-tuples in which Gretapart is the first element and Greta is the third element aside from the given pair of ordered quadruples. See the previous note.
} 
So, even with regard to issues about the argument places themselves, 4P arguably does a better job of mimicking Absoluteness than does 3P.

Finally, we should note that even if parthood $_{\mathrm{m}}$ is a four-place relation, we can use it to define various non-fundamental parthood relations that have fewer argument places. Here, for example, is a definition of a two-place relation that seems to deserve the title parthood simpliciter:

Part Simpliciter $\quad \mathrm{x}$ is a part simpliciter of $\mathrm{y}=\mathrm{df}$. $\exists \mathrm{r}(\mathrm{x}$ exactly occupies $\mathrm{r}) \& \forall \mathrm{r}[\mathrm{x}$ exactly occupies $\left.r \rightarrow \exists r 2\left(x_{\mathrm{r}}<{ }_{\mathrm{r} 2} \mathrm{y}\right)\right]$

To say that $\mathrm{x}$ is a part simpliciter of $\mathrm{y}$, according to this definition, is to say that $\mathrm{x}$ has a location, and for any such location $\mathrm{r}, \mathrm{x}$ at $\mathrm{r}$ is a $\operatorname{part}_{\mathrm{m}}$ of $\mathrm{y}$, at some location of $\mathrm{y}$. In other words, $\mathrm{x}$ can be found somewhere, and wherever $\mathrm{x}$ can be found, it will there be a part $\mathrm{m}$ of $\mathrm{y}$, at some location of y.

Likewise, we can define various relations that are three-place and that behave in accordance with the principles discussed in section 3. Consider, for example, the following definitions, which I take to require no unpacking:

Time-Slice Parthood

Part Location Parthood $\mathrm{x}$ is a part $\mathrm{ts}_{\mathrm{s}}$ of $\mathrm{y}$ at $\mathrm{t}=\mathrm{df}$. (i) $\mathrm{t}$ is a global time-slice, (ii) there are subregions $r 1$ and $r 2$ of $t$ such that $x$ at $r 1$ is a $\operatorname{part}_{\mathrm{m}}$ of $\mathrm{y}$ at $\mathrm{r} 2$, and (iii) for any subregion $\mathrm{r}$ of $\mathrm{t}$, if $\mathrm{x}$ exactly occupies $r$, then there is some subregion $r^{*}$ of $t$ such that $\mathrm{x}$ at $\mathrm{r}$ is a part $\mathrm{m}_{\mathrm{m}}$ of $\mathrm{y}$ at $\mathrm{r}^{*}$.

$\mathrm{x}$ is a part $\mathrm{pl}_{\mathrm{l}}$ of $\mathrm{y}$ at $\mathrm{r}=\mathrm{df}$. $\mathrm{r}$ is a spacetime region, and there is some spacetime region $\mathrm{r}^{*}$ such that $\mathrm{x}$ at $\mathrm{r}$ is a part $_{\mathrm{m}}$ of $\mathrm{y}$ at $\mathrm{r}^{*}$.

Given the availability of definitions like these, the friend of 4P need not deny the existence or intelligibility of the relevant two-place or three-place relations; she need only deny their fundamentality.

This completes the case for preferring $4 \mathrm{P}$ over $3 \mathrm{P}$, given multi-location.

\section{Formal Considerations}

Many philosophers believe that if parthood $_{\mathrm{m}}$ is a two-place relation, then it has certain familiar formal properties, such as reflexivity and transitivity. What should these philosophers say about the formal properties of parthood $_{\mathrm{m}}$ on the assumption that it is a four-place relation? In this section I will tentatively recommend certain answers to that question.

I will not attempt to argue for or against any claim of the form 'if parthood $_{m}$ is two-place, then it has formal property P' or 'if parthood $\mathrm{m}_{\mathrm{m}}$ is four-place, then it has formal property Q.' For example, I neither endorse nor reject the claim that if parthood $_{m}$ is two-place, then it obeys a Uniqueness of Composition principle.

Rather, what I will attempt to do is to begin to address questions like the following: "Suppose that one has no settled opinion as to the adicity of parthood $\mathrm{m}_{\mathrm{m}}$, but one is convinced that if parthood $_{\mathrm{m}}$ is two-place, then it obeys a Uniqueness of Composition principle. In that case, is there any analogous principle that one will find it natural to adopt if one becomes convinced that parthood $_{\mathrm{m}}$ is in fact a four-place, rather than a two-place, relation? If so, what is the principle?" My ambitions here are modest: I hope only to uncover some considerations that provide guidance on these questions, not to settle them. 
I will begin by setting out some familiar definitions and principles framed in terms of a two-place parthood predicate; I will then suggest what I take to be natural analogues of these principles, framed in terms of a four-place parthood predicate. First, some definitions:

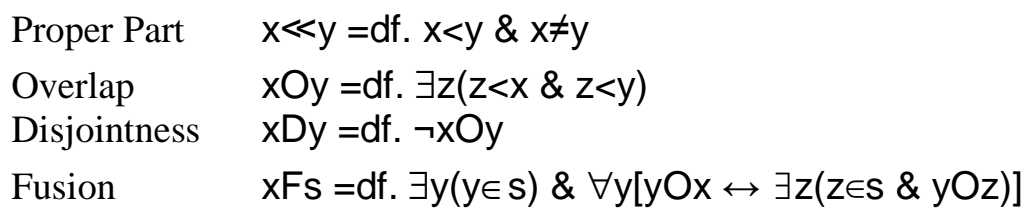

A proper part of a thing is a part of a thing that is not identical with that thing; things overlap iff they share a common part; and they are disjoint iff they don't overlap. The fusion predicate is here defined in terms of set membership ${ }^{44}$ and overlap: $x$ fuses $s$ just in case (i) $s$ has at least one member and (ii) a thing overlaps $\mathrm{x}$ just in case it overlaps some member of $\mathrm{s}$.

Next, some principles. Most would agree that if parthood $_{m}$ is two-place, then it is governed at least by the following:

$\begin{array}{ll}\text { Reflexivity } & \forall x(x<x) \\ \text { Transitivity } & \forall x \forall y \forall z[(x<y \& y<z) \rightarrow x<z] \\ \text { Weak Supplementation (WSP) } & \forall x \forall y[(x<y) \rightarrow \exists z(z \ll y \& z D x)]\end{array}$

Of these, I take it that only WSP requires comment: it says that if a thing has a proper part, then it has a second proper part that is disjoint from the first. ${ }^{45}$

Some philosophers think that parthood $\mathrm{m}_{\mathrm{m}}$, if two-place, is governed not merely by the three principles above but also by one or both of the following:

$$
\begin{array}{ll}
\text { Universalism } & \forall s[\exists x(x \in s) \rightarrow \exists x(x F s)] \\
\text { Uniqueness } & \forall s \forall x \forall y[(x F s \& y F s) \rightarrow x=y]
\end{array}
$$

Universalism says that every non-empty set has at least one fusion; Uniqueness says that nothing has more than one fusion.

\footnotetext{
${ }^{44}$ A fusion predicate can also be defined schematically (see Hovda (2009) for discussion) or by appeal to plural quantifiers and variables ( $\mathrm{x}$ fuses the $\mathrm{Ys}=\mathrm{df} . \forall \mathrm{z}[\mathrm{zOx} \leftrightarrow \exists \mathrm{y}(\mathrm{y}$ is among the $\mathrm{Ys} \& \mathrm{yOz})]$ ). See Lewis (1991: 73) for a different definition of 'fusion' in terms of plural quantifiers and variables.

${ }^{45}$ This is prominently discussed in Simons (1987); it is meant to be (like Reflexivity and Transitivity) acceptable to friends and foes of Uniqueness and to friends and foes of Universalism. But some foes of Uniqueness (e.g., Thomson 1998) may doubt it for the following reason. Suppose that Lump and Goliath are two different fusions of the same particles. Suppose further that at least one of them, say Lump, is a part of the other, Goliath. (Thomson takes each of them to be a part of the other.) Then, since they are nonidentical, Lump is a proper part of Goliath. But, contrary to WSP, Goliath does not have any parts that are disjoint from Lump, since they are both fusions of the same particles. There is a variant of WSP, however, that captures the core intuition underlying WSP while avoiding this worry:

$$
\text { Quasi-Supplementation (QS) } \quad \forall x \forall y[(x<y \& x \neq y) \rightarrow \exists z \exists w(z<y \& w<y \& z D w)]
$$

QS says that if a thing has a part with which it is not numerically identical, then it has parts that are disjoint from each other, though not necessarily from the original part. This captures Simons's important insight (used to motivate WSP) that "surely if a universe is complex (i.e. has proper parts at all) then at least two of these parts will be disjoint" (1987: 27). The Thomson-inspired treatment of Lump and Goliath poses no threat to QS: clearly each of those objects has disjoint parts (e.g., a particle in Goliath's left foot and one in his right foot).
} 
Can we formulate analogues of these principles that are appropriate to a four-place parthood relation? What further principles, if any, govern the interaction between our four-place parthood relation and the subregion and exact occupation relations?

I have already made forays in this direction. I have suggested that parthood $\mathrm{m}_{\mathrm{m}}$ is governed by Transitivity4P and that its interaction with exact occupation is plausibly governed by LLP. To state these and other principles formally, I will continue to use ' $\mathrm{x}_{\mathrm{r} 1}<_{\mathrm{r} 2} \mathrm{y}$ ' for ' $\mathrm{x}$ at $\mathrm{r} 1$ is a part $\mathrm{m}_{\mathrm{m}}$ of $\mathrm{y}$ at $r 2$ ' and ' $r 1$ 드2' for ' $r 1$ is a subregion of r2', and I will introduce two new symbols: 'Rr' for ' $r$ is a spacetime region' and ' $\mathrm{x} \otimes r$ ' for ' $\mathrm{x}$ exactly occupies $r$ '. This lets us write out a non-modal variant of LLP as:

$$
\text { LLP* } \quad \forall x \forall r 1 \forall y \forall r 2\left[x_{r 1}<r 2 y \rightarrow(x \otimes r 1 \& y \otimes r 2)\right]
$$

This says that if $\mathrm{x}$ at $\mathrm{r} 1$ is a part $\mathrm{m}$ of $\mathrm{y}$ at $\mathrm{r} 2$, then $\mathrm{x}$ exactly occupies $\mathrm{r} 1$ and $\mathrm{y}$ exactly occupies $\mathrm{r} 2$. I suspect that many philosophers will also find it highly plausible that if $\mathrm{x}$ at $\mathrm{r} 1$ is a part $\mathrm{m}_{\mathrm{m}}$ of $\mathrm{y}$ at $\mathrm{r} 2$, and if $\mathrm{r} 1$ and $\mathrm{r} 2$ are both spacetime regions, ${ }^{46}$ then $\mathrm{r} 1$ will be a subregion of $\mathrm{r} 2$. We can express this formally as follows:

Inheritance $\quad \forall x \forall r 1 \forall y \forall r 2\left[\left(x_{r 1}<r 2 y \& R r 1 \& R r 2\right) \rightarrow r 1\right.$ 드2 $]$

Inheritance is meant to capture the thought that parts lie within their wholes. We will have more to say about the interaction of parthood $\mathrm{m}_{\mathrm{m}}$ and exact occupation below.

Consider next the relatively uncontroversial view that parthood $_{m}$ is governed by a reflexivity principle or by some close analogue of it. A two-place parthood relation could be reflexive in the strict sense: $\forall \mathrm{x}(\mathrm{x}<\mathrm{x})$. To formulate a counterpart of this principle appropriate to our four-place relation, we will need to take LLP* into account. Thus we should not say: $\forall x \forall r\left(x_{r}<_{r} x\right)$. Together with LLP*, that would entail that everything exactly occupies everything: $\forall x \forall r(x \otimes r)$ ! Instead we should say that a thing is a part of itself at each of its locations. In other words, if a thing exactly occupies something, then the thing, there, is a part $\mathrm{m}_{\mathrm{m}}$ of itself, there:

$$
\text { Reflexivity4P } \forall \mathrm{x} \forall \mathrm{r}\left(\mathrm{x} \otimes \mathrm{r} \rightarrow \mathrm{x}_{\mathrm{r}}<\mathrm{r}\right)
$$

It may be helpful to return to the relation of pair-parthood defined in section 4 :

$$
\text { p is a pair-part of } p^{*}=d f . \exists x \exists r 1 \exists y \exists r 2\left(p=\langle x, r 1\rangle \& p^{*}=\langle y, r 2\rangle \& x_{r 1}<r_{2} y\right)
$$

Setting aside the possibility that a thing $\mathrm{x}$ at a location $\mathrm{r} 1$ is a $\operatorname{part}_{\mathrm{m}}$ of a thing $\mathrm{y}$ at a location $\mathrm{r} 2$ even though one or both of the ordered pairs $\langle\mathrm{x}, \mathrm{r} 1\rangle$ and $\langle\mathrm{y}, \mathrm{r} 2\rangle$ fails to exist, Reflexivity4P is

\footnotetext{
${ }^{46}$ I include this clause because I do not want to rule out the possibility that there are entities other than spacetime regions that can serve as the relata (in the 'subscripted positions') of parthood ${ }_{\mathrm{m}}$. In my (2007: 191) I suggested that one material object, at a given moment of its personal time, can be a part $\mathrm{m}_{\mathrm{m}}$ of another material object, at a given moment of its personal time, where these moments of personal time are presumably not to be identified with spacetime regions. But it seems wrong to suggest that the first such moment must therefore be a subregion of the second such moment. Likewise, one might think that there are such things as (non-spatiotemporal) argument places in properties and relations, and perhaps even in the entities (if such there be) expressed by sentential operators; one might think that these argument places, though obviously non-spatiotemporal, are quite literally exactly occupied by various entities; and one might think that they too can serve as the relata of parthood $\mathrm{m}_{\mathrm{m}}$. But again it seems wrong to suggest that such argument places would be subregions of one another.
} 
equivalent to the claim that pair-parthood is reflexive over the domain of occupation pairs, where an occupation pair is an ordered pair whose first element exactly occupies its second element.

\subsection{Weak Supplementation}

So far we have stated counterparts of what I take to be the two most widely accepted mereological principles: Transitivity and Reflexivity. The third relatively uncontroversial principle mentioned above is WSP. To state a counterpart of WSP appropriate to four-place parthood, it will be convenient to have a new technical term. We will say that a two-place relation $\mathrm{R}$ is weakly supplementive if and only if $\forall \mathrm{x} \forall \mathrm{y}[(\mathrm{xRy} \& \mathrm{x} \neq \mathrm{y}) \rightarrow \exists \mathrm{z}[(\mathrm{zRy} \& \mathrm{z} \neq \mathrm{y}) \& \neg \exists \mathrm{w}(\mathrm{wRx} \&$ wRz)]]. WSP tells us, in the shorthand permitted by our definitions, that parthood $_{m}$ is weakly supplementive.

To determine how to formulate the most natural 4P-appropriate counterpart of WSP, I suggest that we look to the examples already established by Transitivity4P and Reflexivity4P. If we set aside the possibility that a thing $\mathrm{x}$ at a location $\mathrm{r} 1$ is a part $\mathrm{m}_{\mathrm{m}}$ of a thing $\mathrm{y}$ at a location $\mathrm{r} 2$ despite the non-existence of $\langle\mathrm{x}, \mathrm{r} 1\rangle$ or $\langle\mathrm{y}, \mathrm{r} 2\rangle$, Transivity4P is equivalent to the claim that pairparthood is transitive, and Reflexivity4P is equivalent to the claim that pair-parthood is reflexive over the domain of occupation pairs. I suggest, then, that the most natural 4P-appropriate counterpart of WSP will be a principle that is equivalent (setting aside the aforementioned possibility) to the claim that pair-parthood is weakly supplementive, at least over the domain of occupation pairs. The most straightforward way to state such a principle, it seems to me, is as follows:

$$
\begin{aligned}
& \mathrm{WSP}_{4 \mathrm{P}}: \forall \mathrm{x} \forall \mathrm{r} 1 \forall \mathrm{y} \forall \mathrm{r} 2\left[( \mathrm { x } _ { \mathrm { r } 1 } < _ { \mathrm { r } 2 } \mathrm { y } \& ( \mathrm { x } \neq \mathrm { y } \vee \mathrm { r } 1 \neq \mathrm { r } 2 ) ) \rightarrow \exists \mathrm { z } \exists \mathrm { r } 3 \left[\mathrm{z}_{\mathrm{r} 3}<\mathrm{r} 2 \mathrm{y} \&(\mathrm{z} \neq \mathrm{y} \vee \mathrm{r} 3 \neq \mathrm{r} 2) \&\right.\right. \\
& \neg \exists \mathrm{w} \exists \mathrm{r} 4\left(\mathrm{w}_{\mathrm{r} 4}<{ }_{\mathrm{r} 3} \mathrm{z} \& \mathrm{w}_{\left.\left.\left.\mathrm{r} 4<<_{\mathrm{r} 1} \mathrm{x}\right)\right]\right]}\right.
\end{aligned}
$$

To see that this is equivalent to the claim that pair-parthood is weakly supplementive, consider an arbitrarily chosen foursome of entities, a, ra, b, and rb, and suppose:

$$
a_{r a}<_{r b} b \&(a \neq b \vee r a \neq r b)
$$

(i) is equivalent to:

$$
\langle a, r a\rangle \text { is a pair-part of }\langle b, r b\rangle \&\langle a, r a\rangle \neq\langle b, r b\rangle
$$

$\mathrm{WSP}_{4 \mathrm{P}}$, together with (i), entails

$$
\exists z \exists r 3\left[z_{r 3}<_{r b} b \&(z \neq b \vee r 3 \neq r b) \& \neg \exists w \exists r 4\left(w_{r 4}<_{r 3} z \& w_{r 4}<r a\right)\right]
$$

And the claim that pair-parthood is weakly supplementive, together with (ii), entails

$$
\begin{aligned}
& \exists p\left[p \text { is a pair-part of }\langle b, r b\rangle \& p \neq\langle b, r b\rangle \& \neg \exists p^{*}\left(p^{*} \text { is a pair-part of } p \& p^{*}\right. \text { is }\right. \\
& \text { a pair-part of }\langle a, r a\rangle)]
\end{aligned}
$$

But (iii) and (iv) are equivalent! So $\mathrm{WSP}_{4 \mathrm{P}}$ can be derived from the claim that pair-parthood is weakly supplementive, and (setting aside the possibility of missing ordered pairs) vice versa. 
Again, I take this to be good evidence that $\mathrm{WSP}_{4 \mathrm{P}}$ is the closest 4P-appropriate counterpart of Weak Supplementation.

We can state this principle in a more compact form if we define four-place counterparts of the familiar two-place predicates for proper parthood, overlap, and disjointness:

$$
\begin{array}{ll}
\text { Proper Part }_{4 \mathrm{P}} & \mathrm{x}_{\mathrm{r} 1} \ll_{\mathrm{r} 2} \mathrm{y}=\text { df. } x_{\mathrm{r} 1}<_{\mathrm{r} 2} \mathrm{y} \&(\mathrm{x} \neq \mathrm{y} \vee \mathrm{r} 1 \neq \mathrm{r} 2) \\
\text { Overlap }_{4 \mathrm{P}} & \mathrm{x}_{\mathrm{r} 1} \mathrm{O}_{\mathrm{r} 2} \mathrm{y}=\text { df. } \exists z \exists r 3\left(z_{\mathrm{r} 3}<_{\mathrm{r} 1} \mathrm{x} \& \mathrm{z}_{\left.\mathrm{r} 3<{ }_{\mathrm{r} 2} \mathrm{y}\right)}\right. \\
\text { Disjointness }_{4 \mathrm{P}} & \mathrm{x}_{\mathrm{r} 1} \mathrm{D}_{\mathrm{r} 2} \mathrm{y}=\text { df. } \neg \mathrm{x}_{\mathrm{r} 1} \mathrm{O}_{\mathrm{r} 2} \mathrm{y}
\end{array}
$$

This lets us abbreviate $\mathrm{WSP}_{4 \mathrm{P}}$ as

$$
\mathrm{WSP}_{4 \mathrm{~Pa}} \quad \forall \mathrm{x} \forall \mathrm{r} 1 \forall \mathrm{y} \forall \mathrm{r} 2\left[\mathrm{x}_{\mathrm{r} 1} \ll_{\mathrm{r} 2} \mathrm{y} \rightarrow \exists \mathrm{z} \exists \mathrm{r} 3\left(\mathrm{z}_{\mathrm{r} 3} \ll{ }_{\mathrm{r} 2} \mathrm{y} \& \mathrm{z}_{\mathrm{r} 3} \mathrm{D}_{\mathrm{r} 1} \mathrm{x}\right)\right]^{47}
$$

Before we move on, it may be worthwhile to note a potential application of the suggestion that $\mathrm{WSP}_{4 \mathrm{P}}$ is the closest $4 \mathrm{P}$-appropriate counterpart of Weak Supplementation.

In a recent paper, Nikk Effingham and John Robson (2007) argue that endurantism is threatened by the following case:

A certain brick, Brick ${ }_{l}$, travels backward in time repeatedly, so that it exists at a certain time, $\mathrm{t}_{100}$, 'many times over'. At that time there exist what appear to be one hundred bricks, call them Brick $_{1} \ldots$ Brick $_{100}$, though in fact each of them is identical to Brick $_{1}$ (on one or another of its journeys to the time $\mathrm{t}_{100}$ ), and a bricklayer arranges 'them' into what appears to be a brick wall, Wall.

Effingham and Robson write that

There is a principle of mereology known as the Weak Supplementation Principle (WSP) which states that every object with a proper part has another proper part that does not overlap the first. If Brick $_{1}$, Brick $_{2}, \ldots$, Brick ${ }_{100}$ composed a wall, WSP would be false. Consider: any object that was a part of the wall would have to overlap some brick, and as every brick is Brick if $_{1}$ that object overlaps some brick it overlaps Brick . Therefore if at $\mathrm{t}_{100}$ Brick $_{1}$, Brick $_{2}, \ldots$, Brick ${ }_{100}$ composed a wall, there would be no object that could be a proper part of the wall that does not overlap Brick . $_{\text {. }}$ Given Brick ${ }_{1}$ is a proper part of that wall, WSP would then be false (2007: 634-635).

If what I have suggested so far is correct, then the endurantist who accepts multi-location ${ }^{48}$ has a clear response. He should begin by noting that he (qua multi-locationist) has powerful reasons for holding that parthood $_{\mathrm{m}}$ is a four-place relation, where these reasons are completely independent of worries about time travel scenarios. He should then note that the core intuition underlying WSP will give rise to different principles, depending upon one's view about the adicity of parthood $_{\mathrm{m}}$ : for example, in conjunction with the view that parthood $_{\mathrm{m}}$ is two-place, that intuition points toward

\footnotetext{
${ }^{47}$ Similarly, the closest 4P-appropriate counterpart of QS (discussed in note 45) is: $\mathrm{QS}_{4 \mathrm{P}}$ $\forall x \forall r 1\left[\exists y \exists r 2\left(y_{r 2}<r_{1} x \&(x \neq y \vee r 1 \neq r 2)\right) \rightarrow \exists y \exists r 2 \exists z \exists r 3\left(y_{r 2}<r_{r} x \& z_{r 3}<r_{r} x \& y_{r 2} D_{r 3} z\right)\right]$.

${ }^{48}$ As we saw in section 3 , if an endurantist rejects multi-location and takes instants of time to be simple, sui generis entities, rather than spacetime regions of a certain sort, then 3P remains tenable for him. As a result, he apparently has no independent motivation to eschew WSP (or its 3P-appropriate counterpart) in favor of $\mathrm{WSP}_{4 \mathrm{~Pa}}$. He may, of course, appeal to the Effingham-Robson case, together with plausibility of endurantism, as motivation enough for shifting to $4 \mathrm{P}$ and its associated principles.
} 
WSP itself. But in conjunction with the view that parthood $_{\mathrm{m}}$ is four-place, that intuition points toward WSP $4 \mathrm{~Pa}$. Finally, he should note that Effingham and Robson's time travel case poses no threat at all to $\mathrm{WSP}_{4 \mathrm{~Pa}}$. Their case respects that principle.

To see this, recall that instants of time, for the multi-locationist, are merely spacetime regions of a special sort - global time slices. So $t_{100}$ will be such a region. Presumably Wall

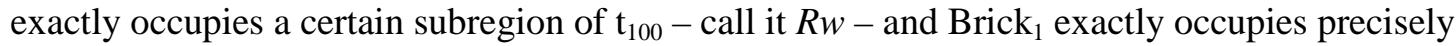
one hundred different non-overlapping, brick-shaped subregions of $\mathrm{Rw}$ - call them $R_{l} \ldots R_{100}-$ where $\mathrm{Rw}$ is the sum or union of these regions. In that case, we can say that Brick ${ }_{1}$ at $\mathrm{R}_{1}$ is not merely a part $_{m}$ of Wall at Rw, but further, a proper part $_{m}$, since it's true that either Brick $\neq$ Wall or $\mathrm{R} 1 \neq \mathrm{Rw}$. (In fact both non-identities hold.) So we can write:

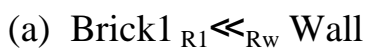

The conjunction of (a) and $\mathrm{WSP}_{4 \mathrm{~Pa}}$ entails that some $\mathrm{z}$, at some $\mathrm{r} 3$, is also a proper part of Wall at $\mathrm{RW}$ and is disjoint from Brick $_{1}$ at $\mathrm{R}_{1}$ :

(b) $\exists \mathrm{z} \exists \mathrm{r} 3\left(\mathrm{z}_{\mathrm{r} 3} \ll_{\mathrm{Rw}}\right.$ Wall \& $\mathrm{z}_{\mathrm{r} 3} \mathrm{D}_{\mathrm{R} 1}$ Brick $\left._{1}\right)$

It may initially seem that (b) is false. After all, aren't Effingham and Robson right when they say that every part of Wall overlaps Brick ${ }_{1}$ ? Presumably there is a sense in which this is right, but that doesn't show that (b) is false. Given our definitions, (b) tells us that there is a $\mathrm{z}$ and an $\mathrm{r} 3$ of which the following hold:

(b) $\quad \mathrm{z}_{\mathrm{r} 3}<_{\mathrm{Rw}}$ Wall \& $(\mathrm{z} \neq$ Wall $\vee \mathrm{r} 3 \neq \mathrm{Rw})$

$\left(\mathrm{b}_{2}\right) \quad \neg \exists \mathrm{w} \exists \mathrm{r} 4\left(\mathrm{w}_{\mathrm{r} 4}<_{\mathrm{r} 3} \mathrm{Z} \& \mathrm{w}_{\mathrm{r} 4}<_{\mathrm{R} 1} \mathrm{Brick}_{1}\right)$

To see there are such things, begin with $\left(\mathrm{b}_{1}\right)$. Can we find $\mathrm{a} z$ and an $\mathrm{r} 3$ such that $\mathrm{z}$ at $\mathrm{r} 3$ is a part $\mathrm{m}$ of Wall at $\mathrm{Rw}$ but either $\mathrm{z} \neq \mathrm{W}$ all or $\mathrm{r} 3 \neq \mathrm{Rw}$ ? That's easy. Pick anything that's intuitively a proper part of Wall at $\mathrm{t}_{100}$ and any subregion of $\mathrm{Rw}$ that the thing exactly occupies. Here are two ordered pairs that do the job:

First pair: $\left\langle\mathrm{G}, \mathrm{R}_{1 \mathrm{subG}}\right\rangle$, where $\mathrm{G}$ is a particular grain of sand that helps to compose Brick $_{1}$ throughout its career, and $\mathrm{R}_{1 \text { subG }}$ is a tiny, grain-of-sand-shaped subregion of the brick-shaped region $\mathrm{R}_{1}$, and $\mathrm{G}$ exactly occupies $\mathrm{R}_{1 \text { subG. }}$.

Second pair: $\left\langle\right.$ Brick $\left._{1}, \mathrm{R}_{100}\right\rangle$, where $\mathrm{R}_{100}$ is a brick-shaped region on the opposite end of Wall from $R_{1}$, and $R_{100}$ is exactly occupied by Brick ${ }_{1}$.

Since $\mathrm{G}$ at $\mathrm{R}_{1 \text { subG }}$ is a part $\mathrm{m}_{\mathrm{m}}$ of Wall at $\mathrm{Rw}$ and either $\mathrm{G} \neq \mathrm{Wall}$ or $\mathrm{R}_{1 \text { subG }} \neq \mathrm{Rw}$ (in fact both nonidenties hold), the first pair does the job. Likewise for the second pair.

But does either of these pairs satisfy $\left(b_{2}\right)$ ? Begin with the first pair. Here we need to ask: is there a w and an $\mathrm{r} 4$ such that $\mathrm{w}$ at $\mathrm{r} 4$ is a part $_{\mathrm{m}}$ of $\mathrm{G}$ at $\mathrm{R}_{1 \text { subG }}$ and $\mathrm{w}$ at $\mathrm{r} 4$ is a part $\mathrm{m}_{\mathrm{m}}$ of Brick $_{1}$ at $\mathrm{R}_{1}$ ? If the answer is "Yes", then the first pair does not satisfy $\left(\mathrm{b}_{2}\right)$; otherwise it does. The answer is "Yes". Here is such a w and an $r 4: G$ and $R_{1 \text { subG }}$. After all, $G$ at $R_{1 \text { subG }}$ is a part ${ }_{m}$ of $G$ at $R_{1 \text { subG }}$ (by Reflexivity4P) and $G$ at $R_{1 \text { subG }}$ is a part $\mathrm{m}_{\mathrm{m}}$ of Brick at $\mathrm{R}_{1}$ (which I take it we can see intuitively, given that $R_{1 \text { subG }}$ is a subregion of $R_{1}$ ). In other words, $G$ at $R_{1 \text { subG }}$ is not disjoint from Brick ${ }_{1}$ at $R_{1}$. 
So let us try the second pair. We must ask: is there a w and an $\mathrm{r} 4$ such that $\mathrm{w}$ at $\mathrm{r} 4$ is a part $_{\mathrm{m}}$ of Brick ${ }_{1}$ at $\mathrm{R}_{100}$ and $\mathrm{w}$ at $\mathrm{r} 4$ is a part $\mathrm{m}_{\mathrm{m}}$ of Brick $_{1}$ at $\mathrm{R}_{1}$ ? No. Consider all the ordered $\langle\mathrm{w}, \mathrm{r} 4\rangle$ pairs such that w at $\mathrm{r} 4$ is a part $\mathrm{m}_{\mathrm{m}}$ of Brick at $R_{l}$. On the assumption that any such $\mathrm{r} 4$ is a spacetime region, Inheritance tells us that any such $\mathrm{r} 4$ must be a subregion of $\mathrm{R}_{1}$. Now consider all the ordered $\langle\mathrm{w}, \mathrm{r} 4\rangle$ pairs such that $\mathrm{w}$ at $\mathrm{r} 4$ is a part $\mathrm{m}_{\mathrm{m}}$ of Brick at $R_{100}$. On the assumption that any such $\mathrm{r} 4$ is a spacetime region, Inheritance tells us that any such $\mathrm{r} 4$ must be a subregion of $R_{100}$. So, in order for it to be true that there is a w and an $\mathrm{r} 4$ such that $\mathrm{w}$ at $\mathrm{r} 4$ is a part $\mathrm{m}_{\mathrm{m}}$ of Brick both at $\mathrm{R}_{1}$ and at $R_{100}$, those last two regions would need to have a common subregion. But since $R_{1}$ and $R_{100}$ are on opposite ends of the wall, they have no common subregion. So we can conclude that there is no pair $\langle\mathrm{w}, \mathrm{r} 4\rangle$ such that $\mathrm{w}$ at $\mathrm{r} 4$ is a part $\mathrm{m}_{\mathrm{m}}$ of $\mathrm{Brick}_{1}$ both at $\mathrm{R}_{1}$ and at $\mathrm{R}_{100}$. In other words, Brick at $\mathrm{R}_{100}$ is disjoint from Brick ${ }_{1}$ at $\mathrm{R}_{1}$, in the sense of 'disjoint' relevant to $\mathrm{WSP}_{4 \mathrm{~Pa}}$, and defined above. Thus (b) is true, and the Effingham-Robson case ends up respecting $\mathrm{WSP}_{4 \mathrm{~Pa}}$. (It also respects the weaker principle $\mathrm{QS}_{4 \mathrm{P}}$, mentioned in note 47.)

Four-place parthood, here argued for on independent grounds, has a beneficial byproduct: it defuses what initially appeared to be a serious threat to endurantism. This completes my discussion of Weak Supplementation and its 4P-appropriate counterpart.

\subsection{Uniqueness}

Now we can turn to the task of stating 4P-appropriate counterparts of the much more controversial Universalism and Uniqueness principles. Both principles will employ a three-place fusion predicate that can be defined as follows:

$$
\begin{array}{ll}
\text { Fusion }_{4 \mathrm{P}} & \mathrm{x}_{\mathrm{r} 1} \mathrm{Fs}=\mathrm{df} . \exists \mathrm{y}(\mathrm{y} \in \mathrm{s}) \& \forall \mathrm{y}[\mathrm{y} \in \mathrm{s} \rightarrow \exists \mathrm{z} \exists \mathrm{r} 2(\mathrm{y}=\langle\mathrm{z}, \mathrm{r} 2\rangle)] \& \forall \mathrm{y} \forall \mathrm{r} 2\left[\mathrm{y}_{\mathrm{r} 2} \mathrm{O}_{\mathrm{r} 1} \mathrm{x} \leftrightarrow\right. \\
& \left.\exists \mathrm{z}\left(\mathrm{z} \in \mathrm{s} \& \exists \mathrm{w} \exists \mathrm{r} 3\left(\mathrm{z}=\langle\mathrm{w}, \mathrm{r} 3\rangle \& \mathrm{y}_{\mathrm{r} 2} \mathrm{O}_{\mathrm{r} 3} \mathrm{w}\right)\right)\right]
\end{array}
$$

According to this definition, to say that a thing $\mathrm{x}$ fuses a set $\mathrm{s}$ at a region $\mathrm{r} 1$ is to say that: (i) $\mathrm{s}$ is a non-empty set of ordered pairs, and (ii) for any y and any $\mathrm{r} 2$, y at $\mathrm{r} 2$ overlaps $\mathrm{x}$ at $\mathrm{r} 1$ if and only if there is a w and an $\mathrm{r} 3$ such that: $\mathrm{y}$ at $\mathrm{r} 2$ overlaps $\mathrm{w}$ at $\mathrm{r} 3$, and $\langle\mathrm{w}, \mathrm{r} 3\rangle$ is a member of $\mathrm{s}$. This lets us state a counterpart of Uniqueness:

$$
\text { Uniqueness }_{4 \mathrm{P}} \quad \forall s \forall x \forall r 1 \forall y \forall r 2\left[\left(x_{r 1} F s \& y_{r 2} F s\right) \rightarrow(x=y \& r 1=r 2)\right]
$$

This is equivalent to the claim that pair-parthood has the formal property that the original Uniqueness principle attributes to parthood ${ }_{\mathrm{m}}$ itself. (I will leave it to the reader to convince himor herself of this.)

Uniqueness $_{4 \mathrm{P}}$ tells us that no $\mathrm{s}$ has more than one fusion pair (ordered pair $\langle\mathrm{x}, \mathrm{r}\rangle$ such that $x$ fuses $s$ at $r$ ). Intuitively, it tells us that some things, at some locations of those things, compose no more than one further thing, at no more than one location of that further thing.

To illustrate, suppose that a statue-shaped lump of clay, Lump, fuses set $\mathrm{s}$ at region R, where $\mathrm{s}$ is a set of ordered pairs, the first element of each of these pairs being some particle of clay or other, and the second element being a region exactly occupied by the first element. Further, suppose that a clay statue, Goliath, fuses s, at some region $\mathrm{R}^{*}$. Then, according to Uniqueness $_{4 \mathrm{P}}$, Goliath=Lump and $\mathrm{R}^{*}=\mathrm{R}$. This is what we expect from any principle that claims to be an analogue of Uniqueness. However, Uniqueness ${ }_{4 \mathrm{P}}$ has three additional features worth noting right away. 
(1) Suppose that object o exactly occupies region Ro and fuses set $s$ there, where $s=\{\langle a$, $\mathrm{Ra}\rangle,\langle\mathrm{b}, \mathrm{Rb}\rangle$ \}. Roughly, this means that $\mathrm{o}$ at Ro is composed of $\mathrm{a}$ at $\mathrm{Ra}$ and $\mathrm{b}$ at $\mathrm{Rb}$. Now suppose that $\mathrm{o}$ also exactly occupies a second region, $\mathrm{Ro}^{*}(\neq \mathrm{Ro})$, and fuses set $\mathrm{s}^{*}$ there. Then, given Uniqueness $_{4 \mathrm{P}}$, we can conclude that $\mathrm{s}^{*} \neq\{\langle\mathrm{a}, \mathrm{Ra}\rangle,\langle\mathrm{b}, \mathrm{Rb}\rangle\}$. But this does not entail that o must have different parts ${ }_{\mathrm{m}}$ at $\mathrm{Ro}^{*}$. For it might be that $\mathrm{s}^{*}=\left\{\left\langle\mathrm{a}, \mathrm{Ra}^{*}\right\rangle,\left\langle\mathrm{b}, \mathrm{Rb}^{*}\right\rangle\right\}$, where $\mathrm{Ra}^{*} \neq \mathrm{Ra}$ and/or $\mathrm{Rb} \neq \mathrm{Rb}^{*}$. In that case, it would be natural to say that at $R o, o$ is composed of a and $\mathrm{b}$, at certain locations of those objects, whereas at $R o^{*}, \mathrm{o}$ is 'again' composed of a and b, but at certain other locations of those objects. This is permitted by Uniqueness $4 \mathrm{P}$.

(2) Likewise, Uniqueness 4 P permits a situation in which the very same two multi-located objects, $\mathrm{a}$ and $\mathrm{b}$, compose different things at different locations. For we might have two different objects, $o$ and $o^{*}$, such that o fuses $\{\langle\mathrm{a}, \mathrm{Ra}\rangle,\langle\mathrm{b}, \mathrm{Rb}\rangle\}$ at Ro, whereas $\mathrm{o}^{*}$ fuses $\left\{\left\langle\mathrm{a}, \mathrm{Ra}^{*}\right\rangle,\left\langle\mathrm{b}, \mathrm{Rb}^{*}\right\rangle\right\}$ at $\mathrm{Ro}^{*}$, provided that $\mathrm{Ra} \neq \mathrm{Ra} *$ or $\mathrm{Rb} \neq \mathrm{Rb}$. Thus Uniqueness $4 \mathrm{P}$ is analogous to a principle governing 'time-indexed' parthood that forbids a single set of things from having more than one fusion at a single instant of time, but that does not forbid a single set of things from having one fusion at one time and a different fusion at a different time.

(3) Finally, Uniqueness 4 P permits Effingham and Robson's exotic case of Brick and Wall, in which one thing (Brick), at one hundred different locations, composes a second thing (Wall), at the sum or union of those locations. Once again let $\mathrm{Rw}$ be a wall-shaped region exactly occupied by Wall, and let $R_{1} \ldots R_{100}$ be non-intersecting brick-shaped regions whose sum or union is $\mathrm{Rw}$, where each of these brick-shaped regions is exactly occupied by Brick. Lastly, let $\mathrm{s}$ be the set $\left\{\left\langle\right.\right.$ Brick, $\left.R_{1}\right\rangle \ldots\left\langle\right.$ Brick, $\left.R_{100}\right\rangle$. Then we can say: Wall ${ }_{\mathrm{Rw}} \mathrm{Fs}$. That is, Wall at $\mathrm{Rw}$ is a fusion of the set of ordered pairs listed above, where the first member of each of these pairs is Brick, and the second member is one of $\mathrm{R}_{1}$ through $\mathrm{R}_{100}$. So long as this set is fused by no more than one thing, and at no more than one region, Uniqueness $\mathrm{S}_{\mathrm{P}}$ is respected. It would be violated if $\mathrm{s}$ were fused by two different things at Rw (e.g., by a wall that could have had different parts and also by a 'mere mass of matter' that couldn't have had different parts), and it would be violated if s were fused by Wall at two different regions. But since there is no suggestion that either of these situations obtains, Uniqueness $4 \mathrm{P}$ is not threatened by the case.

It is instructive to compare and contrast the Brick-Wall case with a version of the LumpGoliath case, in which Lump and Goliath are stipulated to be non-identical despite both fusing the same set at the same region, R. As we have seen, the Brick-Wall case clearly obeys both $\mathrm{WSP}_{4 \mathrm{P}}$ and Uniqueness ${ }_{4 \mathrm{P}}$. The given version of Lump-Goliath case, on the other hand, clearly does not obey Uniqueness ${ }_{4 \mathrm{P}}$. Does it obey $\mathrm{WSP}_{4 \mathrm{P}}$ ? Not if either of the following is true:

$\begin{array}{ll}\text { LG1 } & \text { Lump }_{\mathrm{R}}<{ }_{\mathrm{R}} \text { Goliath } \\ \text { LG2 } & \text { Goliath }{ }_{\mathrm{R}}<{ }_{\mathrm{R}} \text { Lump }\end{array}$

Suppose, e.g., that LG1 is true. Then, since Lump $\neq$ Goliath, the definition Proper Part ${ }_{4 \mathrm{P}}$ gives us:

LG3 Lump $_{\mathrm{R}} \ll_{\mathrm{R}}$ Goliath

Together with $\mathrm{WSP}_{4 \mathrm{~Pa}}$, LG3 yields:

LG4 $\exists x \exists r^{*}\left[x_{r^{*}} \ll{ }_{R}\right.$ Goliath \& $x_{r^{*}} D_{R}$ Lump $]$

In words, LG4 says that some $\mathrm{x}$ and some $\mathrm{r}^{*}$ are such $\mathrm{x}$ at $\mathrm{r}^{*}$ is a proper part of Goliath at $\mathrm{R}$ and $\mathrm{x}$ at $r^{*}$ is disjoint from Lump at R. But it should be easy to see that that is false, given that Goliath 
and Lump fuse the same set at R. So, if LG1 or LG2 is true, then the Lump-Goliath case violates $\mathrm{WSP}_{4 \mathrm{P} .}{ }^{49}$ However, if those claims are false, then Lump (at R) and Goliath (at R) are not proper parts of each other, in which case they respect $\mathrm{WSP}_{4 \mathrm{P}}$ (even if, roughly put, neither has a part that is disjoint from the other). So the principle that most clearly differentiates between the BrickWall case and the Lump-Goliath case is Uniqueness ${ }_{4 \mathrm{p}}$ : the Brick-Wall case obeys it, whereas the Lump-Goliath case does not. ${ }^{50}$

So much for Uniqueness 4 P. There are, of course, many other principles stated in terms of our four-place parthood predicate that have some claim to be counterparts of Uniqueness. I do not mean to suggest that these other principles are uninteresting or too distant from Uniqueness to be worth discussing. But, in light of its equivalence to the uniqueness principle governing pairparthood, I do think that Uniqueness $\mathrm{SP}_{\mathrm{P}}$ is the closest $4 \mathrm{P}$-appropriate counterpart of the original principle.

\subsection{Universalism}

Now we are ready to formulate a counterpart of Universalism. No one should want to assert that every set has a fusion pair. In order for a set to have a fusion pair at all, the set must be nonempty, and each of its members must be an ordered pair, and each of these ordered pairs must be such that its first element, at its second element, is a part ${ }_{m}$ of something, somewhere. But in that case, given LLP*, each such ordered pair must be an occupation pair, an ordered pair whose first element exactly occupies its second element. Our counterpart of Universalism, then, will say that every non-empty set of occupation pairs (every ' $\mathrm{o}$-set') has at least one fusion pair. Or, in symbols:

$$
\text { Universalism }_{4 P} \forall s\left[[\exists y(y \in S) \& \forall y(y \in S \rightarrow \exists x \exists r 1(y=\langle x, r 1\rangle \& x \otimes r 1))] \rightarrow \exists x \exists r 1\left(x_{r 1} F s\right)\right]
$$

As our guidelines dictate, this is equivalent to the claim that pair-parthood has the formal property (over the domain of occupation pairs) that Universalism attributes to parthood $\mathrm{m}_{\mathrm{m}}$.

To get a feel for Universalism 4 , let Re be a spacetime region exactly occupied by the Eiffel Tower, and let Rn be a spacetime region exactly occupied by my nose. Then Universalism $_{4 \mathrm{P}}$ tells us that if there is such a thing as the set $\{\langle$ the Eiffel Tower, Re $\rangle,\langle$ my nose, $\mathrm{Rn}\rangle$ \}, then there is some $\mathrm{x}$ that fuses that set at some $\mathrm{r} 1$. Likewise, if Re and Re* are two different spacetime regions each exactly occupied by the Eiffel Tower, then the principle tells us that if there is such a thing as the set $\left\{\langle\right.$ the Eiffel Tower, Re $\rangle$, $\left\langle\right.$ the Eiffel Tower, Re* $\left.{ }^{*}\right\}$, then some y fuses that set at some $\mathrm{r} 2$. The principle is silent as to what fuses this last set - perhaps the Eiffel Tower itself, perhaps something else. ${ }^{51}$ This completes my discussion of Universalism and its 4Pappropriate counterpart.

${ }^{49}$ Even in the presence of LG1 or LG2, the Lump-Goliath case still respects

$$
\mathrm{QS}_{4 \mathrm{P}} \quad \forall x \forall \mathrm{r} 1\left[\exists \mathrm{y} \exists \mathrm{r} 2\left(\mathrm{y}_{\mathrm{r} 2}<\mathrm{r} 1 \mathrm{x} \&(\mathrm{x} \neq \mathrm{y} \vee \mathrm{r} 1 \neq \mathrm{r} 2)\right) \rightarrow \exists \mathrm{y} \exists \mathrm{r} 2 \exists \mathrm{z} \exists \mathrm{r} 3\left(\mathrm{y}_{\mathrm{r} 2}<_{\mathrm{r} 1} \mathrm{x} \& \mathrm{z}_{\mathrm{r} 3}<_{\mathrm{r} 1} \mathrm{x} \& \mathrm{y}_{\mathrm{r} 2} \mathrm{D}_{\mathrm{r} 3} \mathrm{z}\right)\right]
$$

For this is just the four-place counterpart of the principle that says that if a thing has a part with which it is not identical, then it has parts that are disjoint from each other (though perhaps not from the first part).

Again, Lump and Goliath clearly obey this. See note 45.

${ }^{50}$ Thanks to Ben Caplan for discussion of this point.

${ }^{51}$ Obviously, Universalism $4 \mathrm{P}$ places no restrictions on which o-sets have fusion pairs. It allows for fusions of things no two of which ever exist at the same time. It even allows for fusions of things no two of which are located in the same spacetime (if there are multiple spacetimes). This is all very much in the spirit of the original Univeralism principle framed in terms of the two-place parthood predicate. But many philosophers will accept only a restricted fusion principle. It may be worthwhile, therefore, to see how such a principle can be stated. As a representative example, we can focus on the idea that fusion is universal for sets of 


\subsection{Loose Ends}

I will close this section by returning to issues about the interaction between parthood $\mathrm{m}_{\mathrm{m}}$ and exact occupation. There are two central principles connecting these relations that virtually everyone would be willing to accept. The first is gestured at by the slogan: parts lie within their wholes. Or, alternatively, by the slogan: a whole goes at least as far as any of its parts. This is captured formally by Inheritance. It says that if $\mathrm{x}$ at $\mathrm{r} 1$ is a $\operatorname{part}_{\mathrm{m}}$ of $\mathrm{y}$ at $\mathrm{r} 2$, and if moreover $\mathrm{r} 1$ and $\mathrm{r} 2$ are both spacetime regions, then $\mathrm{r} 1$ is a subregion of $\mathrm{r} 2$.

Whereas the first principle tells us that a whole goes at least as far as its parts, the second principle tells us that a composite whole (one with proper parts) goes no farther than its proper parts. In other words, if a thing is composite (at a region), then any region that intersects that region will intersect a location of at least one of the thing's proper parts. Stick a pin into a location of a composite, and you will have stuck that pin into a location of at least one proper part of that composite. To express this formally, we can begin by defining an intersection predicate in terms of the subregion predicate:

\section{Intersection $\quad$ r1INTr2 $=$ df. $\exists r 3(r 3 \sqsubseteq r 1 \& r 3 \sqsubseteq r 2)$}

In words, regions intersect when they have a common subregion. Next we define a compositeness predicate:

$$
\text { Composite } \quad x C r 1=d f . \exists y \exists r 2\left(y_{r 2} \ll \ll_{r 1} x\right)
$$

That is to say, a thing $\mathrm{x}$ is a composite at a region $\mathrm{r} 1$ iff some $\mathrm{y}$ at some $\mathrm{r} 2$ is a proper part of $\mathrm{x}$ at r1. This lets us state the second principle connecting parthood ${ }_{m}$ and exact occupation as:

$$
\begin{array}{ll}
\text { Delegation } & \forall x \forall r 1 \forall r 2\left[( x C r 1 \& R r 1 \& R r 2 \& r 2 I N T r 1 ) \rightarrow \exists y \exists r 3 \left(y_{r 3} \ll_{r 1} x \&\right.\right. \\
& r 2 I N T r 3)]
\end{array}
$$

This says that if a thing $\mathrm{x}$ is composite at a region $\mathrm{r} 1$, then any region $\mathrm{r} 2$ that intersects $\mathrm{r} 1$ also intersects a region $\mathrm{r} 3$ at which something is a proper part of $\mathrm{x}$ at $\mathrm{r} 1$. Together with LLP*, it tells us that if a thing $\mathrm{x}$ is composite at a region $\mathrm{r} 1$, then $\mathrm{x}$ exactly occupies $\mathrm{r} 1$, and any region $\mathrm{r} 2$ that intersects $\mathrm{r} 1$ also intersects some region $\mathrm{r} 3$ that is exactly occupied by something $\mathrm{y}$ that, at $\mathrm{r} 3$, is a proper part of $\mathrm{x}$ at $\mathrm{r} 1$.

One last loose end remains. I have helped myself to the predicates 'is a spacetime region' and 'is a subregion of.' The former predicate will remain undefined here. Must the latter go undefined too? I would not be deeply averse to this if there were no adequate alternative, but there seem to be two potentially viable strategies for defining 'subregion' - either in terms of ' part $_{\mathrm{m}}$ ' and 'region', or in terms of 'subset' and 'region'. Here is the first:

things that all exist at the same instant of time. Here it will be convenient to use a new undefined predicate, 'Tr', for ' $r$ is a global time-slice'. This lets us state the restricted fusion principle as:

$$
\begin{aligned}
\text { Universalism4Pr } & \forall s[[\exists y(y \in s) \& \forall y \exists r 2(T r 2 \&(y \in s \rightarrow \exists x \exists r 1(y=\langle x, r 1\rangle \& x \otimes r 1 \& r 1 \subseteq r 2)))] \rightarrow \\
& \left.\exists x \exists r 1\left(x_{r 1} F s\right)\right]
\end{aligned}
$$

In words, this says that for any o-set of ordered pairs whose second members are all subregions of some common global time-slice, there is something that fuses this set somewhere. 
Subregion $1 \quad \mathrm{r} 1$ 드 $2=\mathrm{df}$. $\mathrm{r} 1$ is a spacetime region, $\mathrm{r} 2$ is a spacetime region, and $\mathrm{r} 1$ is a part simpliciter of $\mathrm{r} 2$,

where 'part simpliciter' is defined in terms of four-place parthood in accordance with the definition given in section 4 . According to that definition, $\mathrm{r} 1$ is a part simpliciter of $\mathrm{r} 2$ just in case

$$
\exists r 1^{*}\left(r 1 \otimes r 1^{*}\right) \& \forall r 1^{*}\left[r 1 \otimes r 1^{*} \rightarrow \exists r 2^{*}\left(r 1_{r 1^{*}<r 2^{*}} r\right)\right]
$$

In other words, in order for $\mathrm{r} 1$ to count as a part simpliciter of $\mathrm{r} 2, \mathrm{r} 1$ must itself have a location (exactly occupy something), and it must be such that for each of its locations, $\mathrm{r}^{*}$, there is some location $\mathrm{r} 2 *$ of $\mathrm{r} 2$ such that $\mathrm{r} 1$ at $\mathrm{r} 1^{*}$ is a $\operatorname{part}_{\mathrm{m}}$ of $\mathrm{r} 2$ at $\mathrm{r} 2 *$. This may seem odd. We typically think of regions as being locations of non-regions. But do regions themselves have locations? Perhaps. I see no obvious problem with the suggestion that each region exactly occupies itself and that no region exactly occupies any other region. ${ }^{52} \mathrm{With}$ this suggestion in place, it is plausible that regions are often parts simpliciter of other regions. So Subregion1 strikes me as tenable, at least prima facie. Here is the second definition:

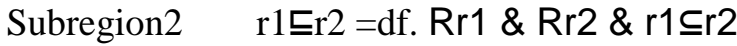

Those who subscribe to this definition would presumably go on to define 'region' as 'non-empty set of spacetime points', where 'spacetime point' might then be taken as primitive. Subregion2 has the obvious drawback of identifying what appear to be concrete entities, spacetime regions, with what appear to be abstract entities, certain sorts of sets. But for those who think that they can see their way clear of this problem, the definition is available.

\section{Conclusion}

In sections 2-4 I argued that if multi-location is true, then parthood $\mathrm{m}_{\mathrm{m}}$ is a four-place relation - one that is plausibly taken to hold between an entity $\mathrm{x}$, a location $\mathrm{r} 1$ of $\mathrm{x}$, an entity $\mathrm{y}$, and a location $\mathrm{r} 2$ of $y$. When both of the 'entities' in question are material objects, it is natural to assume that their locations will always be spacetime regions, but this is not strictly required by anything that I have said. Moreover, I have left open the possibility that some of the 'entities' in question - some of the parts and/or some of the wholes - are not material objects, but rather belong to other ontological categories. ${ }^{53}$ Still, the motivations for $4 \mathrm{P}$ itself and for the $4 \mathrm{P}$-appropriate mereological principles discussed in section 5 are all based purely on considerations about material objects and their locations in spacetime.

Finally, I should emphasize that I have argued only for a conditional conclusion: that if multi-location is true, then so is 4P. I have taken no stance on whether we should use this

\footnotetext{
${ }^{52}$ Is there something absurd about the idea of a self-occupying entity? While I would prefer not to say that everything is self-occupying (I doubt that I exactly occupy myself), I see nothing obviously implausible about the view that some things, such as spacetime regions, do self-occupy.

${ }^{53}$ This raises an interesting question: given that such things as states of affairs, propositions, and certain sorts of universals are notorious for their tendency to violate commonly-accepted mereological principles (Lewis 1986b and 1986c), are any of these things better behaved by the lights of our 4P-appropriate counterparts of these principles? If so, then given that $4 \mathrm{P}$ and the associated mereological principles can be motivated purely by appeal to considerations stemming from material objects, this might go some distance toward exonerating some of the states of affairs, propositions, etc., in question. I hope to address this issue in future work.
} 
conclusion as part of a modus ponens argument for $4 \mathrm{P}$ or instead as part of a modus tollens argument against multi-location.

\section{References}

Armstrong, D. M. 1989. Universals: An Opinionated Introduction (Boulder: Westview).

Bricker, P. 1993. 'The Fabric of Space: Intrinsic v. Extrinsic Distance Relations', Midwest Studies in Philosophy 18: 271-294

Campbell, K. 1981. 'The Metaphysic of Abstract Particulars', Midwest Studies in Philosophy 6: 477-488.

Donnelly, M. forthcoming. 'Parthood and Multi-location' Oxford Studies in Metaphysics.

Earman, J. 1995. Bangs, Crunches, Whimpers, and Shrieks, Oxford: Oxford University Press.

Effingham, N. and Jon Robson, 2007. 'A Mereological Challenge to Endurantism,' Australasian Journal of Philosophy 85: 633-640.

Ehring, D. 1997. Causation and Persistence (Oxford: Oxford University Press).

Gilmore, C. 2007. 'Time Travel, Coinciding Objects, and Persistence,' Oxford Studies in Metaphysics, vol. 3., pp. 177-198

Haslanger, S. 2003. 'Persistence Through Time', in Loux and Zimmerman, eds., The Oxford Handbook of Metaphysics (Oxford: Oxford University Press), pp. 315-354.

Hovda, P. 2009. 'What is Classical Mereology?,' Journal of Philosophical Logic 38: 55-82.

Hudson, H. 2001. A Materialist Metaphysics of the Human Person (Ithaca: Cornell).

Hudson, H. 2008. 'Reply to Parsons, Reply to Heller, Reply to Rea', Philosophy and Phenomenological Research 76: 452-470.

Lewis, D. 1983. 'New Work for a Theory of Universals', Australasian Journal of Philosophy 61: 343-377.

Lewis, D. 1986a. On the Plurality of Worlds, Oxford: Blackwell.

Lewis, D. 1986b. 'Against Structural Universals', Australasian Journal of Philosophy 64: 25-46.

Lewis, D. 1986c. 'Comment on Armstrong and Forrest', Australasian Journal of Philosophy 64: 92-93.

Lewis. D. 1991. Parts of Classes, Oxford: Blackwell.

McDaniel, K. 2004. 'Modal Realism with Overlap', Australasian Journal of Philosophy 82: 137152.

McDaniel, K. 2008. ‘Against Composition As Identity’ Analysis 68.2, pp. 128-133.

McDaniel, K. forthcoming 'Structure-Making', Australasian Journal of Philosophy.

Mellor, D. H. 1980. 'On Things and Causes in Spacetime', The British Journal for the Philosophy of Science 31: 282-288.

Newman, A. 2002. The Correspondence Theory of Truth (Cambridge: Cambridge University Press).

Parsons, J. 2007. 'Theories of Location', Oxford Studies in Metaphysics, vol. 3., pp. 201-232.

Parsons, J. 2008. 'Hudson on Location', Philosophy and Phenomenological Research 76: 427435.

Rea, M. 1998. 'Temporal Parts Unmotivated', Philosophical Review 107, 225-260.

Sattig, T. 2006. The Language and Reality of Time (Oxford: Oxford University Press).

Sider, T. 2001. Four Dimensionalism: An Ontology of Persistence and Time, Oxford: Oxford University Press.

Sider, T. 2007. 'Parthood', The Philosophical Review 116: 51-91.

Simons, P. 1987. Parts: A Study in Ontology, Oxford: Clarendon Press.

Thomson, J. J. 1998. 'The Statue and the Clay', Nous 32: 149-173.

van Inwagen, P. 1990. Material Beings, Ithaca: Cornell. 